\title{
FEATURES ASSOCIATED WITH DIET PILL USE IN INDIVIDUALS WITH EATING DISORDERS
}

\author{
Lauren E. Reba-Harrelson
}

A thesis submitted to the faculty of the University of North Carolina at Chapel Hill in partial fulfillment of the requirements for the degree of Master of Arts in the Department of Psychology (Clinical).

Chapel Hill

2006

Approved by:

Advisor: Cynthia M. Bulik, Ph.D.

Reader: Donald H. Baucom, Ph.D.

Reader: Joseph Lowman, Ph.D. 
(C) 2006

Lauren E. Reba-Harrelson

ALL RIGHTS RESERVED 


\begin{abstract}
LAUREN REBA-HARRELSON: Features Associated with Diet Pill Use in Individuals with Eating Disorders

(Under the direction of Cynthia M. Bulik, Ph.D.)

The relation between diet pill use and eating disorder (ED) diagnostic subtype, purging and compensatory behaviors, tobacco and substance use, personality characteristics, and Axis I and Axis II disorders was investigated. The sample included 1315 participants with ED diagnoses and diet pill use data from the multisite, Price Foundation Genetics Studies. Results indicated that diet pill use was associated with increased weight control behaviors, novelty seeking, anxiety disorders, substance use disorders, and borderline personality disorder, and negatively associated with narcissistic personality disorder. Findings suggest that certain clinical and personality variables distinguish individuals with EDs who use diet pills from those who do not. In the ED population, vigilant screening for
\end{abstract} diet pill use is an imperative clinical objective. 


\section{ACKNOWLEDGEMENTS}

The author thanks the Price Foundation for the support of the clinical collection of participants and support of data analysis. The author acknowledges the staff of the Price Foundation Collaborative Group for their efforts in participant screening and clinical assessments. The author is indebted to the participating families for their contribution of time and effort in support of this study. 


\section{TABLE OF CONTENTS}

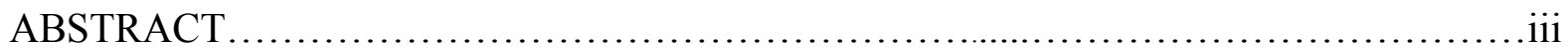

ACKNOWLEDGEMENTS ......................................................

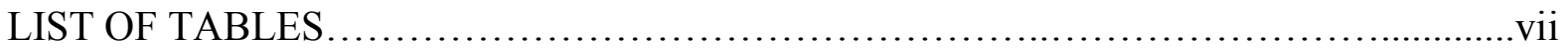

FEATURES ASSOCIATED WITH DIET PILL USE IN INDIVIDUALS WITH

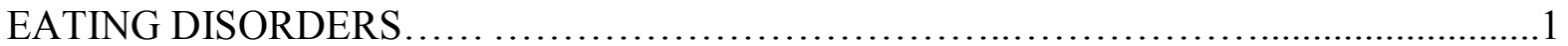

Eating Disorders: Anorexia Nervosa and Bulimia Nervosa..................2

Diet Pill Use in the General Population....................................

Diet Pill Use in Eating Disorders....................................... 15

Safety: Diet Pill Use and Medical Comorbidity in Eating Disorders.........16

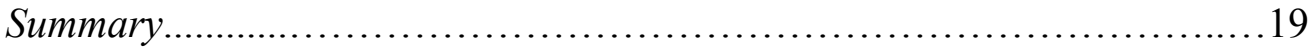

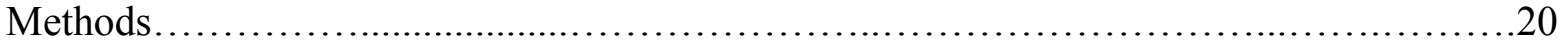

Sample and Procedures...............................................................................20

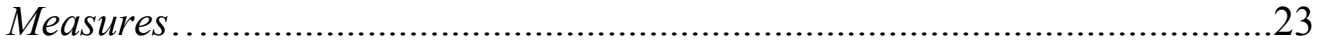

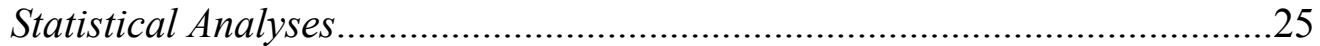

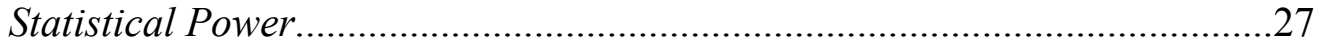

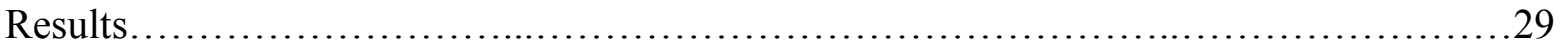


Logistic Regression Analyses.............................................................30

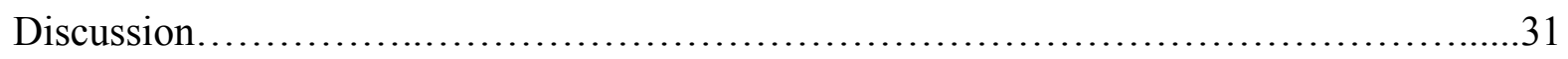

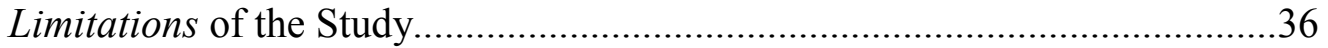

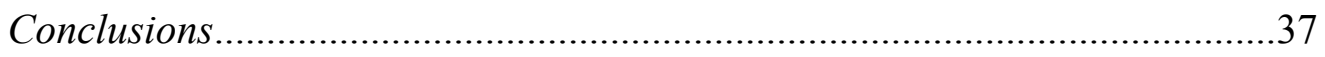

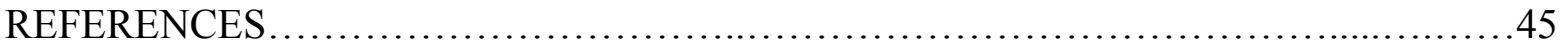




\section{LIST OF TABLES}

Table

Page

1. Demographic characteristics by ED subgroup..................................39

2. Frequency of diet pill use across ED subgroups................................. 40

3. Results from logistic regression analysis (using GEE) predicting odds of diet pill use by vomiting, purging, excessive exercise, tobacco use, caffeine use, and substance use, adjusted for age at interview...

4. Results from logistic regression analyses (using GEE) predicting odds of diet pill use by trait anxiety scores and novelty seeking scores, adjusted for ED subtype and age at interview.

5. Results from logistic regression analyses (using GEE) predicting odds of diet pill use by Axis I and Axis II disorders, adjusted for ED subtype and age at interview...

Graph

1. Age-adjusted rates of diet pill use across ED subgroups. 


\section{FEATURES ASSOCIATED WITH DIET PILL USE IN INDIVIDUALS WITH}

\section{EATING DISORDERS}

Eating disorders (EDs) are acute mental illnesses with significant medical and psychiatric comorbidities. For females ages 15-24, the mortality rate associated with Anorexia Nervosa (AN) is 5\% per decade, the highest rate of any psychiatric disorder (Birmingham, Su, Hlynsky, Goldner, \& Gao, 2005; Sullivan, 1995).

Dill pill use is a salient problem in individuals with EDs, and their use is well documented clinically; however, few studies have investigated their use in large wellcharacterized samples of individuals with eating disorders. The prevalence of diet pill use, medical complications, and their impact on treatment remains unknown. This study sought to determine the prevalence of diet pill use and explore features associated with their use in a large, well-characterized sample of individuals with EDs.

The specific aims were:

Aim 1. To determine the prevalence of lifetime diet pill use in individuals across ED subtypes and the demographic characteristics of those who use.

Hypothesis 1. Individuals with restricting-type anorexia nervosa (RAN) will use diet pills less frequently than those with other subtypes.

Aim 2. To explore the differential patterns of weight loss behaviors including vomiting, purging, excessive exercise, tobacco use, caffeine use, and substance use in individuals who use diet pills, adjusted for age at interview. 
Hypothesis 2. Diet pill use will be associated positively with each purging behavior (vomiting, laxative use, diuretic use, emetic use), excessive exercise, tobacco use, caffeine use and substance use.

Aim 3. To determine the degree to which trait anxiety and novelty seeking are associated with diet pill use, adjusted for age at interview and ED subtype.

Hypothesis 3. Diet pill use will be associated positively with both trait anxiety and novelty seeking.

Aim 4. To determine the prevalence of Axis I and Axis II disorders in individuals with and without diet pill use, adjusted for age at interview and ED subtype.

Hypothesis 4. Diet pill use will be associated positively with Axis I disorders, in particular major depression, anxiety disorders, and substance use disorders. Diet pill use will be associated positively with Axis II disorders, particularly with cluster B disorders.

Adding to the limited literature on diet pill use in individuals with EDs, this study yielded estimates of the prevalence of diet pill use in individuals with EDs, and a well-characterized description of features associated with diet pill use in the ED population. In the long-term, this literature may serve to enhance our understanding of factors independently associated with diet pill use in individuals with eating disorders, and impact future studies developing targeted treatments pertaining to reducing diet pill use in this population.

Eating Disorders: Anorexia Nervosa and Bulimia Nervosa

Clinical Phenomenology 
Eating Disorder diagnoses are characterized by the Diagnostic and Statistical Manual of Mental Disorders, 4th ed., (DSM-IV) as anorexia nervosa (AN) and bulimia nervosa (BN) (American Psychiatric Association, 1994). A third category, eating disorders not otherwise specified (EDNOS), includes binge eating disorder and subthreshold and atypical presentations and represents the largest proportion of individuals presenting for treatment (Fairburn \& Walsh, 2002; Turner \& Bryant-Waugh, 2003). Given an absence of information on diet pill use in individuals with EDNOS, this review will focus on AN and BN.

Anorexia Nervosa.

AN can become a chronic and potentially fatal disorder, with a mean prevalence of $0.3 \%$, and a mortality rate of 5\% per decade (Sullivan, 1995; World Health Organization, 1992). Most commonly beginning during adolescence in women, $\mathrm{AN}$ is characterized by a drive for thinness, an obsessive self-perception of being overweight, and emaciation, with weight dropping below $85 \%$ of ideal body weight. In $D S M-I V$ (APA, 1994), AN is subcategorized as restricting type (RAN), including individuals who do not engage in binge eating or purging behavior (i.e., vomiting, laxative misuse, diuretics or enemas), and binge eating/purging type (ANBP). At present, treatment of AN is complicated by the absence of FDA-approved medications, and the presence of comorbid psychopathology including affective and anxiety disorders (Herzog, Keller, Sacks, Yeh, \& Lavori, 1992). Personality characteristics uniquely associated with AN include high persistence (associated with industriousness), high constraint, (associated with controlled behavior), and low novelty seeking (Casper, Hedeker, \& McClough, 1992; Cassin \& von Ranson, 2005; Klump et al., 2000); traits common in both AN and BN include perfectionism, obsessionality, neuroticism, negative emotionality, harm avoidance, low self- 
directedness, low cooperativeness, and traits associated with avoidant personality disorder

(Cassin \& von Ranson, 2005; Diaz-Marsa, Carrasco, \& Saiz, 2000; Halmi et al., 2000).

\section{Bulimia Nervosa.}

$\mathrm{BN}$ does not include a diagnostic criterion for body weight. Individuals with $\mathrm{BN}$ are typically in the normal weight range, although they may be underweight or overweight (APA, 1994). However, if an individual is underweight and meets other criteria for AN, the AN diagnosis supercedes the $\mathrm{BN}$ diagnosis. With frequent onset in late adolescence, the disorder is characterized by binge eating and purging (or other compensatory behaviors), disproportionate emphasis on weight and body shape, and often impulse control problems (APA, 1994). DSM-IV BN subtypes include purging type (PBN), including those who engage in purging behavior (i.e., vomiting, laxative misuse, diuretics, or enemas), and non-purging type (BNNP), for those who do not purge but use other compensatory behaviors, such as fasting or excessive exercise.

In BN, psychiatric and medical morbidity often includes major depression, anxiety disorders, substance use disorders, and Axis II pathology (Braun, Sunday, \& Halmi, 1994; Brewerton et al., 1995; Bulik, Sullivan, Fear, \& Pickering, 1997; Yates, Sieleni, \& Reich, 1989). Physical complications associated with $\mathrm{BN}$ include fatigue, gastrointestinal problems and acid reflux, esophageal tears, electrolyte imbalances, and cardiac irregularities (Keel, Klump, Miller, McGue, \& Iacono, 2005; Mitchell, Pomeroy, \& Huber, 1988). Although overall mortality does not appear to be elevated in BN (Hoek, 2006; Quadflieg \& Fichter, 2003), these complications run the spectrum of severity, are often irreversible, and occasionally result in death. In terms of personality traits, high impulsivity, sensation seeking and novelty seeking are associated with BN (Cassin \& von Ranson, 2005). It is possible that these traits influence the expression of the ED. In terms of BN, these traits may influence the presence of binge eating and purging 
behaviors, while traits characteristic of AN, such as high constraint and persistence, may lead to restrictive eating behavior.

\section{Eating Disorder Not Otherwise Specified.}

Given DSM-IV classification, eating disorder not otherwise specified (EDNOS) is a catchall category into which all subthreshold forms of AN and BN are cataloged. Data on clinical characteristics, psychiatric comorbidity, causal mechanisms, and treatment interventions for EDNOS are scarce (le Grange et al., 2006), yet it is the most common ED diagnosis in outpatient settings (Turner \& Bryant-Waugh, 2003). Given these factors, the validity of current ED diagnostic criteria has been the subject of considerable recent debate. The few studies that have compared EDNOS with AN and BN have found similar levels of weight and shape concerns, and some differences in demographic and ED symptom variables (le Grange, Loeb, Van Orman, \& Jellar, 2004). The prevalence of diet pill use in individuals with EDNOS is unknown.

\section{Etiology: Genetics and the Environment}

The development of $\mathrm{AN}$ and $\mathrm{BN}$ in individuals is likely to occur due to the interaction of both environmental and genetic influences. Over the past decade, family studies have shown substantial familial aggregation of AN and BN (Fichter \& Noegel, 1990; Wade, Bulik, Neale, \& Kendler, 2000). Twin studies have demonstrated moderate to high heritability for both AN and BN (Keel et al., 2005; Lilenfeld et al., 1998; Strober, Freeman, Lampert, Diamond, \& Kaye, 2000).

In terms of genetic factors, like other psychiatric disorders, $\mathrm{AN}$ and $\mathrm{BN}$ are complex traits - influenced by multiple genes and environmental factors of small to moderate effect. Previous studies suggest the genetic association for AN and BN to be manifested as a broad, obsessive phenotype with core features of perfectionism, anxiety, and behavioral constraint 
(Bulik et al., 2005; Lilenfeld et al., 1998). In terms of diet pill use, this behavior may be an indicator of a broader, underlying phenotype associated with substance abuse, novelty seeking, impulsivity, and trait anxiety---representing a core phenotype for future genetic analyses.

Though family and twin studies have demonstrated that EDs are primarily familial and genetic in origin (Bergen et al., 2003), the environment may play an important role in the expression of underlying predispositions. The concept of gene-environment correlation suggests that an ED personality constellation can influence the susceptibility to environmental stimuli or social choices that increase rather than decrease the likelihood of expression of a genetic predisposition to eating disorders (Rutter, Moffitt, \& Caspi, 2006; Valdar et al., 2006). A review of the effects of nonshared environmental factors (e.g., experiences that are unique to siblings reared in the same family) suggests that differential paternal relationships, body weight teasing, peer group experiences, and life events may influence ED development (Klump, Wonderlich, Lehoux, Lilenfeld, \& Bulik, 2002). In terms of diet pill use in individuals with EDs, environmental factors may include susceptibility to media influence (e.g., buying into the myriad dieting and weight loss advertisements), peer group characteristics (e.g., friends who use risky substances - diet pills, tobacco, alcohol, illegal drugs, thus normalizing these behaviors), or demographic characteristics (e.g., transportation or economic accessibility to diet pills).

\section{Diet pill use in EDs}

From a limited number of studies and clinical observation, it is known that diet pill use is a significant problem in individuals with EDs. In a series of $275 \mathrm{BN}$ patients, Mitchell et al. (1988) found that $52.2 \%$ reported using diet pills. Additionally, in terms of drug safety, Bulik (1992) described toxicity as a potentially noxious feature associated with diet pill use for individuals with EDs. Yet because only a few studies have investigated diet pill use in this 
population, the prevalence of the use of these drugs, whether they pose a medical threat, or how they may impact treatment and recovery remains unknown. Given the physical fragility and medical comorbities associated with these disorders, this lack of data is particularly troublesome.

This study aims: (1) to report what is known regarding prevalence of use, side effects, adverse events, tolerance and withdrawal, and psychiatric comorbidity associated with diet pill use in the general population; (2) to review current research addressing features associated with diet pill use in individuals with EDs, and to explore potential medical comorbidity related to use of these drugs in the ED population; and (3) to examine the relationship between diet pill use and ED diagnostic subtype, purging and compensatory behaviors, tobacco and substance use, personality characteristics, and Axis I and Axis II disorders.

Diet pill use in the general population

Diet pills represent a broad class of substances used for the purpose of stimulating weight loss, ostensibly functioning via mechanisms that suppress appetite or stimulate resting metabolism (Dwyer, Allison, \& Coates, 2005). The potential heatlh impact of these drugsincluding dietary supplements, OTC and prescription weight loss agents is not fully understood. To investigate what is known regarding the effect profile of some of these drugs, this discussion will focus mainly on the drugs which function as appetite suppressants - the "anorectic drugs," affecting the appetite and satiety centers of the brain, and in some cases, involved in recent federal market withdrawal (Carek \& Dickerson, 1999). The two primary classes of anorectic drugs are the noradrenergic agents and the serotonergic agents (Carek \& Dickerson, 1999). This section will explore the prevalence of diet pill use in the general population, the effect and safety 
profile of diet pills (focusing on the anorectic drugs and federal regulation issues) and specifically, the association of diet pill use with anxiety.

\section{Prevalence}

In the United States and Canada, diet pill usage is endorsed by $0.5 \%$ to $3 \%$ of the general adult population (Kann et al., 2000). In the U.S., females use diet pills more than males, with $10.9 \%$ having taken diet pills, powders, or liquids without a doctor's advice to lose weight or to avoid gaining weight (Blanck, Khan, \& Serdula, 2005). Moreover, 7.9\% of women within the normal weight range have reported diet pill use (Jones, Bennett, Olmsted, Lawson, \& Rodin, 2001). Similarly, in a school based sample of Canadian females aged 12-18, Jones et al. found the prevalence of diet pill use to be $2.4 \%$ (Story et al., 1994). In a large sample of 7 th- through 12th-grade American Indian-Alaska Native youths, Story et al. reported that $11 \%$ of adolescent girls reported diet pills use (Khan, Serdula, Bowman, \& Williamson, 2001). Among individuals

with a body mass index (BMI $\mathrm{kg} / \mathrm{m}^{2}$ ) less than $27 \mathrm{~kg} / \mathrm{m}^{2}$, Khan et al. noted that diet pill usage was twice as likely among women as men ( $27.9 \%$ vs. $13.2 \%)$, and almost twice as likely among non-Hispanic white and Hispanic respondents (26.1\% vs. 26.4\%) than in non-Hispanic black respondents (15.0\%) (Nakamura et al., 1999). In a sample of Japanese women, Nakamura et al. found that in women with some history of dieting behavior, $14.3 \%$ were past or current users of diet pills (Blanck et al., 2005). Amongst 12 to 29 year old women in Brazil, 5.1\% were found to have used diet pills in the past 3 months (Nunes, Barros, Anselmo Olinto, Camey, \& Mari, 2003). In a multistate population study, Blanck et al (2005) noted that almost one third of prescription weight loss pill users were not obese before taking pills. One third of users also reported taking nonprescription diet products. Among fenfluramine or dexfenfluramine users, 
one third continued pill use after the market withdrawal and only one quarter received echocardiograms after the dangers of the drug had been exposed (Cuthbert, 1980).

In short, in the general population, regardless of race, ethnicity, and often drug safety, diet pill use is especially prevalent in girls and women - and of note, commonly used by those who are not overweight.

\section{Drug Effects and Drug Safety}

Before discussing effects of diet pills, it is important to define clearly common pharmacological terms used to measure the effects of drugs and drug safety (Meyer \& Quenzer, 2005). Side effects are defined as all drug-receptor interactions beyond those which produce desired physical or behavioral changes, with toxic/adverse effects being side effects with negative medical consequences. In the case of diet pills, side effects would be all effects produced by the drug other than suppression of appetite or metabolic stimulation. Drug tolerance is defined as a diminished response to drug administration after repeated exposure to the drug. Essentially, tolerance refers to when a larger dose of the drug must be administered to receive a biological effect similar to the original dose. Drug withdrawal is associated with the physical dependence model of drug use (Meyer \& Quenzer, 2005). In this model, once an individual has become physically dependent on a drug, attempts to abstain result in highly unpleasant symptoms (known as withdrawal symptoms) which commonly trigger renewed use to

eliminate the symptoms. In the area of psychopharmacology, drug safety is evaluated in terms of a therapeutic index, a ratio comparing the dose of drug required to produce a toxic effect in $50 \%$ of individuals, to the dose that produces the desired effect (e.g., in an antianxiety drug, reduced anxiety) in 50\% of individuals. Drugs may have many therapeutic indices based on each toxic effect. 
Limitations exist in assessing the side effects, tolerance and withdrawal for diet pills. First, limited data exist regarding the safety of diet pills. Carek and Dickerson (1999) note that the long term tolerance of many appetite suppressants has not been adequately evaluated. Further, Anderson (2003) states that we lack adequately powered studies of sufficient duration for both older appetite suppressants and newer drugs, such as Orlistat (a lipitase inhibitor, blocking a percentage of ingested fat from being digested) and Sibutrimine (a monoamine reuptake inhibitor, stopping the reabsorbtion of serotonin and producing appetite suppression). Second, given the broad and varied spectrum of diet pills, assessing the effects of the entire class of drugs is virtually impossible. Given the limited literature, this section will focus primarily on the serotonergic agents (i.e. fenfluramine, and dexfenfluramine) and noradrenergic agents [i.e. diethylpropion, mazindol, phendimetrazine, benzphetamine, phenylpropanolamine (PPA) and phentermine]. As these data are primarily derived from research informing the market withdrawal of certain drugs, it is instructive to review the history of the federal regulation of various diet pills.

\section{Federal Regulation.}

The issue of the U.S government's regulation of diet drugs over the past decade is rife with warnings and withdrawals, and sheds light on the varying safety profiles of this broad class of drugs. In 1994, the passage of the Dietary Supplement Health and Education Act (DSHEA) dramatically changed the regulation process for weight-loss supplements, changing the FDA's role from pre-market authorization to post-market enforcement and shifting the responsibility from government to industry to ensure products were safe and effective (Federal Trade Commission, 2002). DSHEA created a definition for a class of products called "dietary supplements" and established that these products are deemed to be foods in terms of regulation. 
Through this act, two types of weight-control products were created. The first class includes products functioning to treat obesity and non-dietary supplements intended to be used for weight control, with both remaining subject to pre-market approval. The second type includes dietary supplements intended to be used for weight control, as well as all herbal supplements. Premarket approval is not required for this class of products. This class of diet pills therefore has no regulations to ensure appropriate dose recommendations, support of efficacy, quality control, or peer-reviewed studies of toxicities or drug interactions (Lewis \& Strom, 2002). When adverse events occur due to weight loss supplements, it is the responsibility of the physician to report their effects to the FDA's MedWatch Website (www.fda.gov/medwatch). In addition, individuals who use these drugs do so with little or no data regarding what to anticipate and are in the position of using these products at their own risk.

Lacking any market control, the concentration, purity, and effectiveness of a particular drug may vary from brand to brand, or even within batches. Even if manufacturers claim that they have conducted effectiveness trials, administering consistent doses of the active ingredient to each subject in the lab, and demonstrating dose-dependent effects, there is no ability to assure the replication of the effect in the general market (Meyer \& Quenzer, 2005). Thus the pill the consumer takes may not contain the same ingredients, nor quantities of ingredient as measured in the lab. A further compromise of safety exists when the consumer is sold drugs through misleading advertising. Discussed in a U.S. Federal Trade Commission (2002) report on weightloss advertising, the Commission has brought numerous cases against the advertisers of weightloss supplements for making false or misleading advertising claims. The 1990's saw an increase in dietary supplement marketing, many of which are of unproven value or have been linked to serious health risks. 


\section{Behavioral and Neural Effects of Diet Pills.}

In September of 1997, following reports of cardiac valvulopathy in individuals taking the popular diet pill combination "Fen-Phen", the FDA withdrew the serotenergic agents fenfluramine or dexfenfluramine (with or without phentermine) from the U.S. markets. It was determined that these drugs produced an increased risk for two different medical disorders: heart valve abnormalities and elevated blood pressure in the arteries between the heart and lungs. Prior to the Fen-Phen withdrawal, weight-control drug research focused on the serotonin system, with increased 5-HT associated with reduced food intake and appetite in humans and animals (Leibowitz \& Shor-Posner, 1986). The withdrawal of Fen-Phen shifted the focus of appetite suppressant research from the serotonerigic system to other areas that may provide a better safety profile.

Nonadrenergic appetite suppressants share a similar chemical structure and mechanism of action with amphetamines, earning street drug amphetamines the slang "diet pills" due to their potential hypophagic (appetite-reducing) side effects (Meyer \& Quenzer, 2005). Further, nonadrenergic drugs may also share with amphetamines a side effect profile including nervousness, reduced fatigue, irritability, headache, sweating, dry mouth, nausea, constipation, and potential for abuse (Silverstone, 1992). One of the most well-know amphetamine-like compounds, ephedrine, popularly marketed in the 1990's for its effect of reducing appetite and its potential to enhance athletic performance, has recently received much attention due to adverse reactions.

In April, 2004, the FDA banned the sale of dietary supplements containing ephedrine alkaloids based on the results of an Agency for Healthcare Research and Quality evidenced based review. In studies and case reports related to ephedra usage, this review noted the 
following adverse events: 84 deaths, 26 myocardial infarctions, 56 cerebral vascular accidents (strokes or cerebral hemorrhage), 30 "other cardiac" events, 8 "other neurological" events, 40 cases of seizure, and 91 cases of psychiatric events (Shekelle et al., 2003). This review provides sufficient data to conclude that the use of ephedrine, ephedra, or the combination of ephedrine and caffeine is associated with two to three times the risk of nausea, vomiting, psychiatric symptoms such as anxiety and change in mood, autonomic hyperactivity, and palpitations. Although it was found that approximately half of the sentinel events occurred in persons aged 30 years or younger, it is of note that weight was not assessed as a variable in reporting these potentially ephedrine-related adverse events.

As of August, 2005, the FDA was taking steps to remove another noradrenergic agent, phenylpropanolamine (PPA)--commonly used in cold medications and OTC weight loss products, from all drug products and has requested that all drug companies discontinue marketing products containing PPA. Roerig et al. (2003) noted a series of case studies that cited diet pills containing PPA to be associated with adverse reports of elevated blood pressure (Cuthbert, 1980), as well as renal failure (Swenson, Golper, \& Bennett, 1982), seizures (Howrie $\&$ Wolfson, 1983), anxiety and agitation (Dietz, 1981) memory loss (Puar, 1984), and neurological deficits (Johnson, Etter, \& Reeves, 1983). Pilsczek, Karcic, \& Freeman (2003) reported the first case in which Dexatrim (containing PPA) was the cause of myocardial injury in a young woman using recommended dosages for weight control, as well as seven other case reports in which PPA ingestion led to myocardial injury.

\section{Clinical and Regulatory Obstacles.}

Despite U.S. restrictions on and withdrawals of certain compounds contained in weight control products, such regulation is never completely effective. Internet-based "black- 
marketing" has increased accessibility of these agents (Carek \& Dickerson, 1999). Further, our knowledge of the effects of many diet pills is incomplete. Eisenberg et al. (1998) reported more than $42 \%$ of adult Americans use a form of herbal or alternative medicines and that $60 \%$ of patients do not disclose the use of complementary medicine to their physicians. Thus for treatment providers, a two prong barrier exists in assessing an individual's potential usage of diet pills products: disclosure may not occur due these products perceived status as "supplements" or "harmless", and the chemical content, and thus safety of consumption, cannot be certain.

\section{Diet pills and Anxiety.}

In terms of psychiatric side effects, anxiety has been associated with diet pill use. As previously noted, fenfluramine, dexfenfluramine, and PPA have all been correlated with increased anxiety (Dietz, 1981). In a meta-analysis, Shekelle et al. (2003) found that ephedrine and ephedra were associated with 2 to 3 times the risk of psychiatric symptoms including anxiety.

In diet pills, the mechanism which causes increased anxiety may involve the serotonin system. Several studies suggest that the serotonergic system plays an important role in modulating behavioral arousal associated with anxiety states (Charney, Woods, Goodman, \& Heninger, 1987; Tauscher et al., 2001). A study by Abrams et al. (1986) supports the hypothesis that anxiogenic, stimulant drugs (such as stimulant diet pills) selectively act on serotonergic neurons, projecting to a distributed central autonomic and emotional motor control system, and regulating anxiety states and associated physiological and behavioral responses, potentially influencing mood, impulse control, and feeding behavior.

Anxiety disorders are commonly associated with EDs, and evidence suggests that disturbances of 5-HT pathways play a role in increased anxiety in this population (Godart, 
Flament, Lecrubier, \& Jeammet, 2000; Kaye, Bertram et al., 2005). Alterations of these circuits may affect mood and impulse control as well as the motivating and pleasure-related aspects of eating behavior (Kaye, Bailer, Frank, Wagner, \& Henry, 2005). The impact of diet pills use on anxiety in the individuals with EDs will be discussed further in Section B4.d.

\section{Diet Pill Use in Eating Disorders}

Few studies have explored the frequency with which diet pills are consumed in individuals with EDs and across diagnostic subtypes. Clinical observation suggests an elevated frequency of use of these substances in ED patients, and a considerable number of case reports and case series have illustrated adverse events associated with their consumption in this population.

In 275 patients with BN, Mitchell et al.(1988) reported a prevalence of $52.2 \%$ for ever having used diet pills, with $25.1 \%$ reporting use of these pills at least once a day. Roerig et al. (2003) found that $64 \%$ of individuals with EDs used diet pills as a weight control method, with Dexatrim (phenylpropanolamine) favored as the most commonly used brand. The authors identified 167 diet pill and herbal supplement products commonly used by individuals with EDs, and noted that of the products reported, $36.5 \%$ contained stimulants. Of the stimulant diet pills reported, $38 \%$ contained caffeine alone, $11 \%$ contained ephedrine alone, and $57 \%$ contained a combination of caffeine and ephedrine. Further, Bulik (1992) discussed the impact of the effects of diet pills on appetite and weight, tolerance and withdrawal on the perpetuation of ED symptoms. In another study, Bulik (1992) reported that women with BN consumed significantly more caffeinated soda per day than women with $\mathrm{AN}$, and that withdrawal from caffeine use in women with $\mathrm{AN}$ and $\mathrm{BN}$ produced side effects including headache, irritability, craving, restlessness, difficulty concentrating, and change in appetite. 
These studies represent the extent of research conducted assessing use of diet pills in individuals with EDs. They suggest that the prevalence of consumption of these substances in individuals with EDs is considerable, and allude to potential dangers associated their use. However, several limitations of this literature need to be considered. First, diet pill use is a self reported variable. As with use of any self-reported measure, there is the possibility of bias and distortion on the part of the part of the participants. In particular, the tendency to endorse answers to make oneself appear socially desirable has been found to be pervasive of self-report scales (Edwards, 1957). Second, the issue of partial reporting is important to consider. Given the breath of available diet drugs and the probability of individuals using multiple substances (Roerig et al., 2003), it is likely that participants may not report all of the drugs that they use. This may be a particular concern if participants are under time constraints, or if the questionnaire does not state explicitly the task of reporting all drugs used. Finally, given that many of these studies are conducted on clinical samples, comorbidity may be elevated (Berkson, 1946). This type of selection bias occurs when the combination of exposure and disease under study increases the risk of hospital admission, thus leading to a higher exposure rate among the clinical cases than the controls. Lacking substantial, well characterized, ED clinical and population samples to compare, the literature leaves this issue unanswered.

Safety: Diet pill use and medical comorbidity in EDs

Diet pill usage may pose a unique and salient threat to the ED population, already at greater risk for medical complications. Serious complications associated with EDs include cardiac dysfunctions, osteoporosis, menstrual irregularity, gastrointestinal (GI), and psychiatric 
effects. In particular, diet pill use may have the greatest impact on safety in terms of cardiac and GI complications, addictive behaviors and anxiety.

\section{Cardiac complications}

Sudden cardiac death is a serious risk for patients with AN, particularly if long duration of illness and hypokalemia are present (Neumaerker, 1997). Several studies have reported that prior to exercising, the intake of caffeine and ephedrine---a common mixture found in some energy drinks and OTC supplements, can result in an increase in heart rate above that found for exercise alone in healthy individuals (Magkos \& Kavouras, 2004). This pairing may be particularly pernicious in individuals with $\mathrm{AN}$ and $\mathrm{BN}$, who are more likely to engage in excessive exercise and experience cardiovascular complications. Further, use of diet pills containing PPA, associated with elevated blood pressure and agitation (Dietz, 1981) could be of particular harm to an ED population given their vulnerability to cardiac problems (Neumaerker, 1997).

\section{Nause and constipation}

In terms of drugs with nonadrenergic mechanisms of action, the potential effects of nausea and constipation are also concerning for individuals with $\mathrm{AN}$ and $\mathrm{BN}$ who by virtue of their eating disorder are at greater risk for GI problems. In a review of GI complication in AN from the stance of a gastroenterologist, the following issues were noted as common: delayed gastric emptying, gastric motor dysfunction, an impaired hunger and satiety signals, delayed small bowel excretion, and constipation (Chial, McAlpine, \& Camilleri, 2002; Mitchell \& Crow, 2006). More severe complications cited in case studies included gastric dilatation, spontaneous rupture of the stomach, pancreatitis, necrotizing colitis, and perforated ulcer (Chial et al., 2002). Gendall et al. (2005) found that women with childhood GI problems head an earlier onset of BN 
and self-induced vomiting, compared with women without such histories. Use of diet pills by women who may be at greater risk for self-induced vomiting due to childhood GI complications, may add to the risk profile of developing and ED. Moreover, the side effect of nausea may also induce purging behavior.

Addictive potential

Amphetamine-like substances (such as diet pills), with the potential for abuse, could be of particular damage to individuals with $\mathrm{BN}$, who are more likely to engage in novelty seeking behavior, such as concomitant drug abuse (Bulik, 1987b; Silverstone, 1992). Moreover, individuals with BN are more likely to suffer from alcohol use and dependence than controls or individuals with AN (Bulik, 1987a)

Anxiety

Anxiety disorders are highly comorbid with EDs. A lifetime diagnosis of at least one anxiety disorder has been found in $13 \%$ to $75 \%$ of women with $\mathrm{BN}$, and in $20 \%$ to $55 \%$ of women with AN, (Herzog, Sacks et al., 1992; Kaye, Bertram et al., 2005; Laessle, Wittchen, Fichter, \& Pirke, 1989; Schwalberg, Barlow, Alger, \& Howard, 1992). Given the high comorbidity rates and the stimulant effects of certain diet pills (such as those containing caffeine, ephedrine, or PPA), the use of these drugs in an ED population may function to mimic and strengthen familiar, elevated, anxious states. This idea may be supported by data suggesting that in animals, stimulants such as caffeine have reinforcing and anxiogenic properties (Sudakov, Rusakova, \& Medvedeva, 2003; Vautrin, Pelloux, \& Costentin, 2005).

As previously noted, Abrams et al. (2005) support the hypothesis that anxiogenic drugs may function to regulate anxiety states and associated physiological and behavioral responses. Moreover, mounting data point to a dysregulation of serotonin pathways in individuals with AN 
and $\mathrm{BN}$ that may be related to anxiety, behavioral alteration, and body image distortion, and recent studies implicate changes in 5-HT1A and 5-HT2A receptors and the 5-HT transporter (Kaye, Bertram et al., 2005; Kaye, Frank et al., 2005). Of note, given that these serotonin disturbances are present in individuals during illness and persist after recovery, 5-HT alterations may be traits rather than a function of the state of the disorder (Kaye, Frank et al., 2005). It is plausible that use of stimulant diet pills in individuals with EDs functions in an attempt to regulate anxiety secondary to serotenergic deregulation.

Given the association of diet pills with anxiety and their potential to cause physiological symptoms found in anxious states, limiting use of these drugs may be particularly relevant in the treatment of individuals predisposed to elevated anxiety. Further, given the anxiogenic affects of stimulant diet drugs and their potential implication on mood and eating behavior, knowledge of use of these drugs may be of particular relevance in the treatment of individuals with eating disorders.

Given the increased medical risk in EDs, both physiological and psychological safety concerns associated with diet pill usage are particularly relevant to the health and treatment outcomes of these individuals.

\section{Summary}

Diet pill usage may pose a distinct and significant threat to individuals with EDs. EDs are associated with substantial medical complications, many of which can be exacerbated by use of these drugs. Moreover, use of these substances may negatively impact treatment response and recovery in EDs. Effects such as GI problems and nausea, may perpetuate purging behavior, and bear on the successful treatment of these patients. Further, given the common comorbidity of 
anxiety disorders and EDs, use of stimulant diet pills, with anxiogenic effects, may further exacerbate anxiety in these individuals.

As the majority of studies examining the prevalence of usage and the safety profile of these drugs have been conducted in the general population, data do not allow us to determine conclusively their impact in individuals with EDs. In the ED field, limited research and clinical reports suggest that use of these drugs is widespread and problematic in this population.

Given an inadequate body of research examining diet pill usage in the EDs, further investigation is necessary to provide a description of prevalence of use of these agents in individuals with EDs. In a well-characterized sample of individuals with AN and BN, our study: (1) analyzed prevalence of diet pill across ED diagnostic subtypes; and (2) explored features associated with diet pill use, including personality characteristics, purging and compensatory behaviors, substance use, tobacco use, and Axis I and Axis II disorders. The purpose of this study was to provide a relevant contribution to the literature by clarifying the magnitude of the problem and further understanding clinical characteristics of individuals who use diet pills.

\section{Methods}

\section{Sample and Procedures}

Participants are from two of the multisite international Price Foundation Genetic Studies

of Eating Disorders: one focusing on families with BN (“BN Affected Relative Pair Study”) and another focusing on individuals with AN and their parents (“AN Trios"). These studies were designed to identify susceptibility loci involved in risk for eating disorders. Informed consent was obtained from all study participants, and all sites received approval from their local Institutional Review Board. Brief descriptions of each study are provided below. 
BN Affected Relative Pair Study. Probands and male and female biological relatives affected with AN, BN, or eating disorder not otherwise specified (EDNOS) were recruited from 10 sites in North America and Europe including Pittsburgh, New York, Los Angeles, Toronto, Munich, Philadelphia, Pisa, Fargo, Minneapolis, and Boston. Probands were required to meet modified DSM-IV (American Psychiatric Association (APA), 1994) lifetime diagnosis of BN, purging type (PBN), where purging must have included regular vomiting, with other means of purging also allowed, and bingeing and vomiting must have occurred at least twice a week for a duration of at least six months. For the complete list of inclusion and exclusion criteria see Kaye et al. (2004). In addition, they were to be 13-65 years of age, and primarily of European decent (to limit genetic variance). Probands were excluded if they had a lifetime history of any of the following: mental retardation, dementia, organic brain syndromes, psychotic disorders, Turner's syndrome, or any medical condition that could affect appetite, body weight, or eating (e.g., diabetes, and thyroid conditions were excluded if the onset of the disease preceded the onset of the ED). Bipolar I and Bipolar II were excluded only if symptoms of BN occurred exclusively during manic or hypomanic episodes. Probands with neurological disorders were excluded unless seizures developed as a result of trauma and had onset post-ED onset. Individuals who premorbid weight exceeded the BMI for the $95^{\text {th }}$ percentile of their age and gender on (Hebebrand, Himmelmann, Heseker, Schafer, \& Remschmidt, 1996) chart of NHANES epidemiological sample, or whose lifetime BMI exceeded 35 were excluded.

Affected relatives were biologically related to the proband (e.g., siblings, half siblings, cousins, etc.). The inclusion criteria for affected relatives were: (1) they had to be between 13-65 years of age and (2) they had to receive at least one lifetime eating disorder diagnoses. The eating disorder diagnoses were defined as follows: (1) DSM-IV BN, purging type or nonpurging 
type; (2) modified DSM-IV AN (i.e., criterion D not required); (3) EDNOS. Exclusion criteria for affected relatives included all exclusion criteria listed for the probands, with the following additional exclusions: (1) monozygotic twin of the proband; (2) biological parent with an ED, unless there was another affected family member with whom the parent could be paired; (3) a diagnosis of Binge Eating Disorder as the only lifetime eating disorder diagnosis.

AN Trios Study. Male and female probands affected with restrictor (RAN) or purging-type AN (PAN) were recruited from 9 sites in North America and Europe including Pittsburgh, New York, Los Angeles, Toronto, Munich, Pisa, Fargo, Baltimore, and Tulsa. Probands were required to meet the following criteria: (1) modified DSM-IV (APA, 1994) lifetime diagnosis of AN, with or without amenorrhea; (2) low weight that is/was less than $5^{\text {th }}$ percentile of BMIs for age and gender on (Hebebrand et al., 1996) chart of NHANES epidemiological sample; (3) onset prior to age 25; (4) weight that is/was controlled through restricting and/or purging, which includes vomiting, use of laxatives, diuretics, enemas, suppositories, or ipecac; (5) age between 13 and 65; (6) Caucasian (one grandparent from another racial group is acceptable); (7) no lifetime history of binge eating; and (8) study diagnostic criteria were met for at least three years prior to entry into study. This last inclusion criteria ensured that AN individuals were unlikely to develop binge eating in the future, as research has shown that most binge eating develops within the first three years of illness in AN (Eckert, Halmi, Marchi, Grove, \& Crosby, 1995; Eddy et al., 2002; Strober, Freeman, \& Morrell, 1997; Tozzi et al., 2005). Potential participants were excluded if they reported maximum BMI since puberty $>27 \mathrm{~kg} / \mathrm{m}^{2}$ for females and $>27.8 \mathrm{~kg} / \mathrm{m}^{2}$ for males. This exclusion of individuals who were overweight or obese was based on the initial inclusion criteria for the genetic studies which were designed to increase sample homogeneity. 
Affected male and female relatives were included if they met the following criteria: (1) same biological mother and father as the proband; (2) a lifetime diagnosis of modified DSM-IV AN (with or without amenorrhea), BN, or EDNOS; and (3) age 13 to 65. Exclusion criteria were the same as for probands.

If the affected relative was a non-sibling, the inclusion and exclusion criteria for participation were the same as for probands with the additional inclusion criterion that the percent relatedness to the proband must be greater than or equal to $12.5 \%$ (includes half siblings, grandparents, aunts/uncles, first cousins, etc., but not second cousins, first cousins once removed, etc.).

The total number of female participants from these studies available for the present analyses are 1372 individuals with $\mathrm{AN}, \mathrm{BN}$ or EDNOS, with available diet pill information. Individuals were excluded from the analyses if they were male (25), had missing data regarding diet pill use (30), or had missing classification by ED subtype (2). The final sample size was 1315. None of the categories above overlapped.

In result, the sample for the current study consisted of females only, non-missing ED type, and excluded those who had (1) a missing or a worst frequency of 0 times/week, (2) an interview age not equal to age at worst use, and (3) a current frequency of diet pill use of 0 times/week.

Measures

The Price Foundation studies included an extensive assessment battery designed to capture a wide array of dimensions know or hypothesized to be relevant to EDs. The purpose of this battery was to allow for the identification of subphenotypes and relevant covariates to 
enhance and refine linkage analyses. For the purpose of the present investigation, based on the literature, we selected a reduced battery of dimensions relevant to diet pill use in EDs.

Demographic and clinical variables. Data relative to age at interview, age at onset, and duration of illness were included in the analyses. These variables were assessed for all participants using the Price Foundation BN-ARP Screen and the AN-Trios Screen.

Eating Disorder Diagnoses. Lifetime histories of eating disorders and the presence or absence of eating disorder behaviors (e.g. dieting, binge eating, etc.) were assessed with the Structured Interview for Anorexic and Bulimic Disorders (SIAB) (Fichter, Herpertz, Quadflieg, \& Herpertz-Dahlmann, 1998) and with an expanded version of Module H of the Structured Clinical Interview for DSM-IV Axis I Disorders (SCID) (First, Spitzer, Gibbon, \& Williams, 1997). The training procedures for the SIAB and SCID have been described in detail elsewhere (Fichter et al., 1998; First, Spitzer et al., 1997).

Definition of Diet Pill Use. Diet pill use was assessed for all participants using the Price Foundation BN-ARP and the AN-Trios Screen, interviews developed for the study. No validated measures of diet pill use exist, possibly related to the vast number of products available and difficulty characterizing and quantifying diet pill use. The Price Foundation data therefore reflect the best available data to address the research question. Weekly frequency of use was recorded by the interviewer in terms of current use (i.e., "How many diet pills do you currently consume each week) and worst use (i.e., "At worst, how many diet pills did you use per week). Further, the interviewer inquired about and recorded the type or brand of each diet pill used (i.e., ma huang, Dexatrim, etc.).

Personality traits. Temperament and character dimensions were measured with the Temperament and Character Inventory (TCI) (Cloninger, Przybeck, Svrakic, \& Wetzel, 1994). 
This investigation focused on novelty seeking, defined as a heritable bias in the initiation or activation of approach in response to novelty, approach to signals of reward, active avoidance of conditioned signals of punishment, and skilled escape from unconditioned punishment (Cloninger et al., 1994).

State-Trait Anxiety. Trait levels of anxiety were assessed with the State-Trait Anxiety Inventory (STAI Form Y-1) (Spielberger, Gorsuch, \& Luchene, 1970).

Purging and Compensatory Behaviors: Vomiting, laxative use, emetic use, diuretic use, and excessive exercise were assessed with the SIAB (Fichter et al., 1998).

Tobacco Use and Substance Use: Tobacco use was assessed using the Fagerstrom Test for Nicotine Dependence (Fagerstrom, 1978). Substance use was assessed with the Structured Clinical Interview for DSM-IV Axis I Disorders (SCID) (First, Spitzer et al., 1997).

Axis I and II Psychiatric Disorders. Axis I disorders were assessed with the SCID I (First, Spitzer et al., 1997). Personality disorders were assessed with the Structured Clinical Interview for DSM-IV Personality Disorders (SCID-II) (First, Gibbon, Spitzer, Williams, \& Benjamin, 1997). Ananlyses include the following Axis I disorders: Agoraphobia, Generalized Anxiety Disorder, Obsessive-Compulsive Disorder, Panic Disorder, Post-Traumatic Stress Disorder, Social Phobia, Specific Phobia, Bipolar I and Bipolar II disorder. Axis II disorders included were Avoidant Personality Disorder, Antisocial Personality Disorder, Borderline Personality Disorder, Dependent Personality Disorder, Histrionic Personality Disorder, Narcissistic Personality Disorder, and Obsessive Compulsive Personality Disorder. Paranoid, Schizoid, and Schizotypal Personality Disorders were excluded from the analyses due to insufficient sample size. 


\section{Statistical Analyses}

All statistical analyses were conducted using SAS/STAT ${ }^{\circledR} 9.1$ software (SAS Institute, 2004). Analyses were conducted for each aim:

Aim 1. To determine the prevalence of lifetime diet pill use in individuals with EDs across ED subgroups, chi-square tests were used to test between-group differences. In terms of demographic characteristics, analysis of variance (ANOVA) was used to examine if the variability between the means of ED subgroups was significantly greater than variability of scores within the ED groups. For all comparisons, statistical significance was set at $P<0.05$.

Aim 2. Logistic regression analyses provided information regarding associations between vomiting, purging behaviors (laxative use, diuretic use, emetic use), excessive exercise, tobacco use, substance use in individuals and diet pill use. Age was included in the model as a covariate.

Aim 3. To determine the degree to which trait anxiety and novelty seeking is associated with diet pill use, standardized scores on the STAI scales and NS scales were included in a logistic regression model with diet pill use as the outcome variable. ED subtype and age were included in the model as covariates.

Aim 4. To determine the prevalence of Axis I and Axis II disorders in individuals with and without diet pill use, standardized scores on the SCID scales were included in a logistic regression model with diet pill use as the outcome variable. ED subtype and age were included in the model as covariates.

For logistic regression analyses using the BN-ARP data, we corrected for nonindependence using Generalized Estimating Equations (GEE) (Diggle, Liang, \& Zeger, 1994; Liang \& Zeger, 1986; Zeger, Liang, \& Albert, 1988). GEE is a statistical approach based on 
regression techniques that are used to investigate clustered data. In the current study, biologically related family members comprised each cluster in the GEE analyses. However, because our study included family members of varying relatedness (i.e., first, second, and third-degree relatives as well as unrelated controls), the GEE analyses were conducted in two steps. First, models were fit to the data via the GEE method for probands and their siblings only using the exchangeable working correlation matrix to obtain an estimate of the familial correlation among these first-degree relatives. Second, models were re-fit to the entire dataset of relatives using familial correlations estimated from the probands and siblings as the user-defined working correlation matrix. The model parameters and statistics from these models were then used as the final solution. This approach to the analyses can be considered conservative, as the proband/sibling correlations are likely overestimates of the expected correlations among clusters of unrelated individuals and second- and third-degree relatives. Such overestimation is likely to result in fewer, rather than more, significant findings.

\section{Statistical Power.}

Analyses of statistical power of linear regression were conducted for the outcome variable, diet pill use. These analyses were computed using SAS/STAT® 9.1 software (SAS Institute, 2004) using the conventions of Cohen (1988). Using conservative estimates for each analysis, power was calculated for effect size value, $r=0.10$.

Aim 1. Descriptive; Power analyses is not required.

Aim 2. Assuming $\alpha=0.05$, a total sample size of 1345 , and 7 predictor variables (vomiting, laxative use, diuretic use, ipecac use, excessive exercise, substance use, and tobacco use), the figure below illustrates statistical power. 


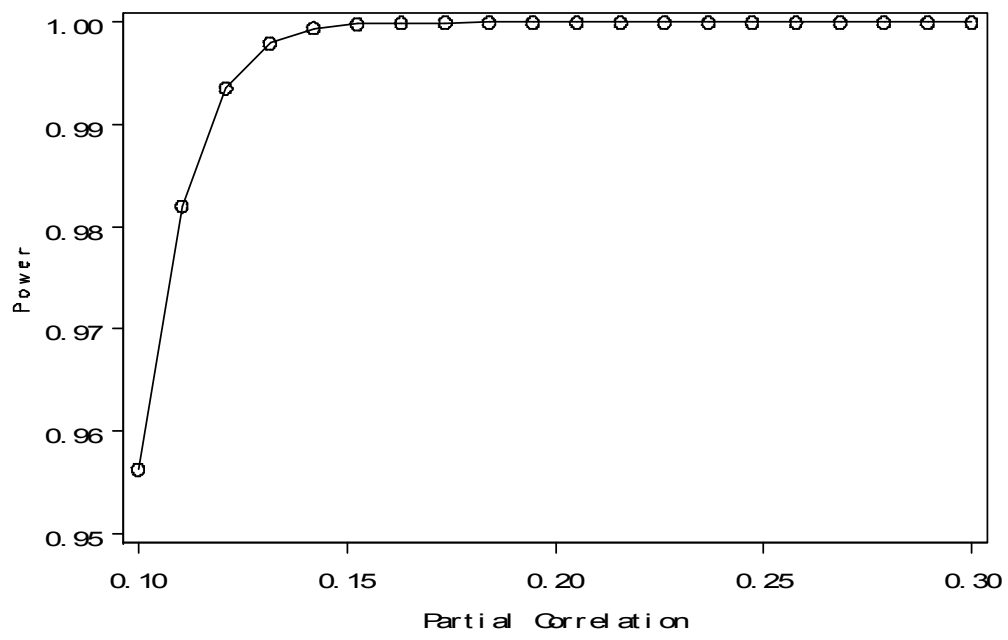

As may be seen and as anticipated, $>90 \%$ statistical power will be achieved for $\mathrm{r}=0.10$.

Aim 3. Using a post-hoc model, assuming $\alpha=0.05$, a total sample size of 1345 , and 2 predictor variables (trait anxiety and novelty seeking), the figure below illustrates statistical power.

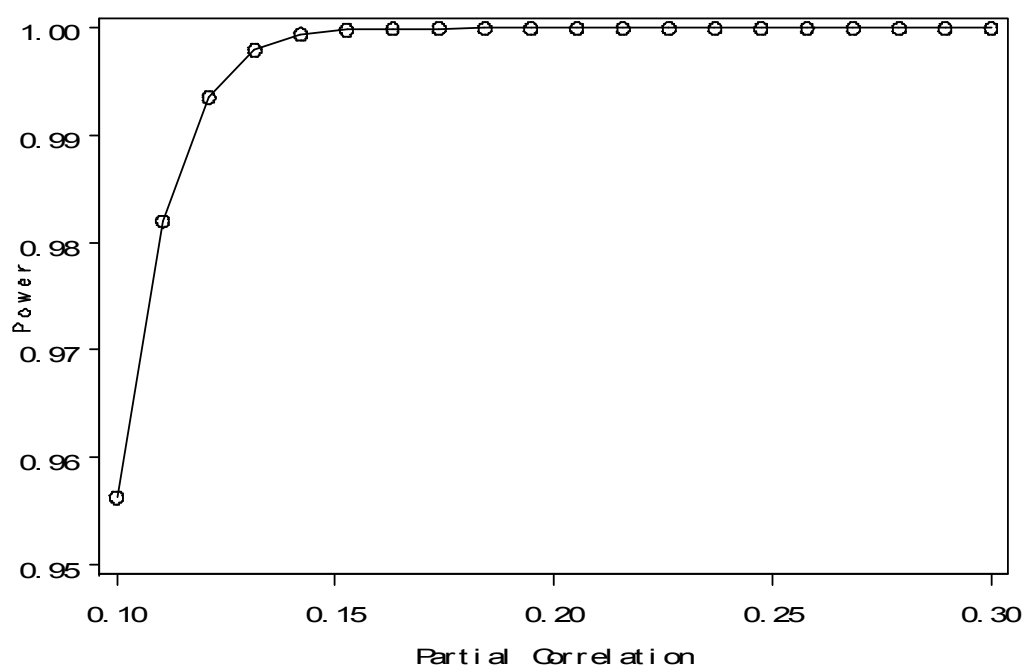

As may be seen and as anticipated, $>90 \%$ statistical power will be achieved for $r=0.10$.

Aim 4. Using a post-hoc model, assuming $\alpha=0.05$, a total sample size of 1345 , and 16 predictor variables (Axis I and Axis II disorders), the figure below illustrates statistical power. 


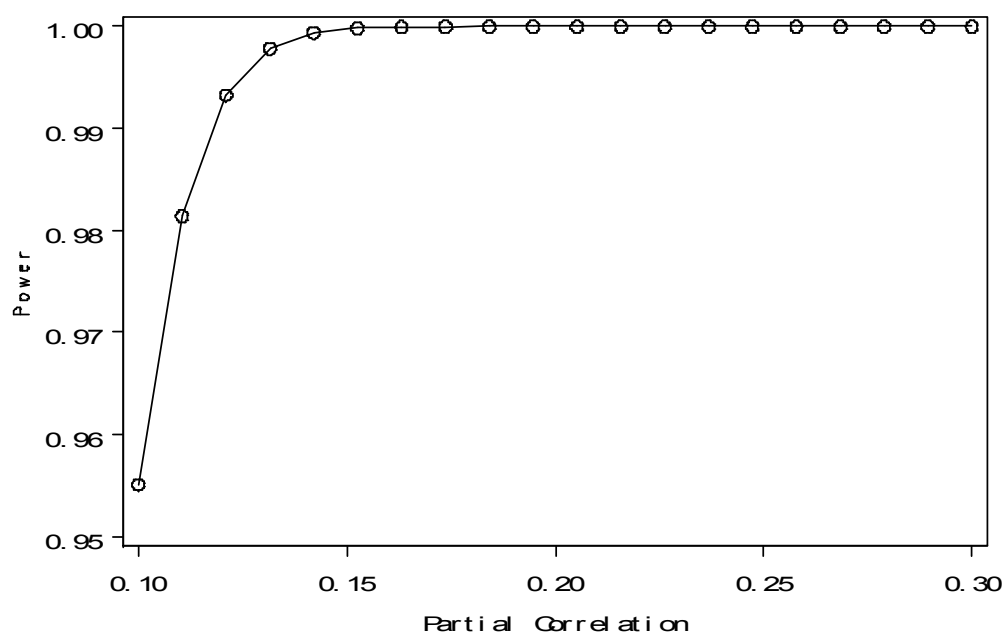

As may be seen and as anticipated, $>90 \%$ statistical power will be achieved for $r=0.10$.

For each relevant aim, the chance of detecting a difference if there is a real difference in the population is 4 out of 5 , meeting the conventions of Cohen for sufficient statistical power (Cohen, 1988). For each analysis, for a partial correlation of 0.10 between each variable and the response variable when controlling for all other response variables in the model, the sample is sufficiently powered to reject the null hypothesis when it is false.

Results

\section{Descriptive Statistics}

Aim 1. Demographic characteristics and prevalence of diet pill use across ED subgroups.

Demographic information for the entire sample is presented in Table 1. Expected differences emerged across ED subtypes. The one-way ANOVA revealed that age at interview $(F(6,1344)=6.96, p<.0001)$, age at onset of $\operatorname{ED}(F(6,1344)=6.95, p<.0001)$, lowest BMI $(F(6,1344)=319.10, p<.0001)$, current BMI $(F(6,1344)=96.28, p<.0001)$, highest BMI 
$(F(6,1344)=88.80, p<.0001)$, and duration of illness $(F(6,1344)=8.75, p<.0001)$ each differed significantly as a function of ED subgroup.

Lifetime diet pill use was endorsed by $32.3 \%(\mathrm{~N}=434)$ of the sample; $66.7 \%(\mathrm{~N}=911)$ reported no diet pill use. Table 2 and Graph 1 present the percentage of individuals who endorsed lifetime diet pill use by ED diagnosis. Using Bonferroni-corrected, age-adjusted comparisons, significantly more individuals in the Purging AN, Binging AN, Purging BN, and ANBN subgroups reported diet pill use than individuals in the Restrictive AN subgroup.

Logistic Regression Analyses

Aim 2. Weight Control Behaviors.

Table 3 presents the odds of diet pill use by weight control behaviors, adjusted for ED subtype and age. Of all the demographic and weight control variables (Aim 2/Table 2), significant differences were found for vomiting $\left(\chi^{2}=40.99, \mathrm{df}=1, \mathrm{p}<.0001\right)$, odds ratio $[\mathrm{OR}]=$ $2.89(95 \%$ confidence intervals $[\mathrm{CI}]=2.09-4.00)$; purging $\left(\chi^{2}=47.87, \mathrm{df}=1, \mathrm{p}<.0001\right), \mathrm{OR}=$ $1.11(95 \% \mathrm{CI}=0.80-1.41)$; caffeine use $\left(\chi^{2}=20.80, \mathrm{df}=1, \mathrm{p}<0.0001\right), \mathrm{OR}=0.78(95 \% \mathrm{CI}$ $=0.44-1.12)$; cannabis use $\left(\chi^{2}=9.86, \mathrm{df}=1, \mathrm{p}=0.0017\right), \mathrm{OR}=0.60(95 \% \mathrm{CI}=0.24-0.96)$; and use of any other substance $\left(\chi^{2}=22.26, \mathrm{df}=1, \mathrm{p}<0.0001\right), \mathrm{OR}=0.93(95 \% \mathrm{CI}=0.56-1.29)$, adjusted for drug use. Vomiting, purging, caffeine use, cannabis use, and use of any substance (other than alcohol or cannabis) were positively associated with use of diet pills.

Aim 3. Novelty Seeking and Anxiety.

Table 4 presents the odds of diet pill use by trait anxiety and novelty seeking. Significant differences emerged for TCI Novelty Seeking $\left(\chi^{2}=6.43, \mathrm{df}=1, \mathrm{p}=.01\right), \mathrm{OR}=1.02(95 \% \mathrm{CI}=$ $1.01-1.02)$; and STAI trait anxiety $\left(\chi^{2}=11.67, \mathrm{df}=1, \mathrm{p}=.0006\right), \mathrm{OR}=1.02(95 \% \mathrm{CI}=1.01-$ 1.03). For a one unit increase in TCI Novelty Seeking, the odds of diet pill use increased by 
$2.3 \%$. For a one unit increase in STAI trait anxiety, the odds of diet pill use increased by $1.6 \%$. Higher scores on both trait anxiety and novelty seeking were associated with higher odds of diet pill use.

Aim 4. Axis I and Axis II disorders.

Table 5 presents the odds of diet pill use by Axis I and Axis II disorders. Positively associated with diet pill use were any anxiety disorder $\left(\chi^{2}=4.57, \mathrm{df}=1, \mathrm{p}=0.03\right), \mathrm{OR}=1.37$ $\left(95 \% \mathrm{CI}=1.03-1.83\right.$; any substance use disorder $\left(\chi^{2}=21.90, \mathrm{df}=1, \mathrm{p}<.0001\right), \mathrm{OR}=2.47(95 \%$ $\mathrm{CI}=1.73-3.52)$; and Borderline Personality disorder $(\mathrm{BPD})\left(\chi^{2}=7.26, \mathrm{df}=1, \mathrm{p}=.007\right), \mathrm{OR}=$ $1.90(95 \%$ CI $=1.21-2.99)$. Individuals with Narcissistic Personality Disorder (NPD) were less likely to use diet pills than those without NPD $\left(\chi^{2}=5.78, \mathrm{df}=1, \mathrm{p}=.02\right), \mathrm{OR}=0.25(95 \% \mathrm{CI}=$ 0.07- 0.86). The definition of any anxiety disorder included Agoraphobia, Generalized Anxiety Disorder, Obsessive-Compulsive Disorder, Panic Disorder, Post-Traumatic Stress Disorder, Social Phobia, Specific Phobia.

\section{Discussion}

Dill pill use is a significant problem in individuals with EDs in the clinic, yet few studies have investigated their use in an ED population. The objective of this study was to determine the prevalence of diet pill use and explore features associated with their use in a large, wellcharacterized sample of individuals with EDs.

In a sample of women with eating disorders, this study found the presence of diet pill use to be positively associated with weight control behaviors (vomiting, purging, caffeine use, cannabis use, any substance use), personality characteristics (increased trait anxiety and novelty seeking), and Axis I and II disorders (any anxiety disorder, any substance use disorder, 
Borderline personality disorder). A negative association was also found between diet pill use and Narcissistic personality disorder.

In terms of prevalence of diet pill use across ED subtypes, and confirming our first hypothesis that individuals with RAN would use diet pills less frequently than those with other subtypes, we found that significantly great numbers of individuals in the PAN, BAN, PBN, and ANBN groups reported use of these substances. The highest prevalence of use was reported by individuals with PAN (41\%), PBN (44\%), and ANBN (42\%).Given that individuals with RAN are more likely to display high constraint characteristics than individuals with purging-type EDs (Casper et al., 1992), a lesser frequency of diet pill use amongst restrictors was not unexpected. Individuals with RAN do not engage in binge eating or purging behavior (i.e., vomiting, laxative misuse, diuretics or enemas), and thus by definition may be less likely to engage in other weight control behaviors such as diet pill use. Alternately, characterization as low in novelty seeking behavior (Cassin \& von Ranson, 2005) may lead to less diet pill use in individuals with RAN.

Our second hypothesis was that diet pill use would be associated positively with each purging behavior (vomiting, laxative use, diuretic use, emetic use), excessive exercise, tobacco use, caffeine use and substance use. Our results supported our hypothesis in part, indicating that diet pill use was associated positively with vomiting, purging, caffeine, cannabis, and any substance use. Given the association between diet pill use and other weight control behaviors, it is notable that individuals who use other strategies to control weight may be more likely to use diet pills. Additionally, the use of diet pills along with other weight control behaviors--alternately hypothesized as risky, may support the existence of an ED subgroup evidencing a cluster of impulsive, problematic behaviors. Previously described as "multi-impulsive", such individuals with bulimia nervosa have been found to display poor response to treatment (Fichter, 
Quadflieg, \& Rief, 1994). Lack of a positive association between diet pill use and excessive exercise and tobacco may be due to the idea that these behaviors are most often favored by individuals who have a phenotypic profile closely linked to obsessive compulsive disorder, for which these ritualized behaviors might be more likely (Davis \& Kaptein, 2006).

Regarding trait and personality features, we hypothesized that diet pill use would be associated positively with both trait anxiety and novelty seeking. Our data supported this hypothesis, indicating that novelty seeking and trait anxiety are both positively associated with diet pill use. In terms of novelty seeking, although this characteristic has been consistently associated with BN, behaviors most often discussed in relation to this attribute and EDs are general substance abuse, stealing, sexual activity, and self-injury (Cassin \& von Ranson, 2005). Within the broad category of substance use, diet pill use can be seen as a novel/risky behavior and should be specifically considered as potentially present in ED individuals with impulsive characteristics.

Regarding trait anxiety, given the association between this feature and diet pill use and the anxiogenic properties of some diet pills (Dietz, 1981; Shekelle et al., 2003), targeting use of these drugs is particularly relevant in an ED population, holding a well-documented susceptibility to anxiety (Keel et al., 2005). Though the use of potentially anxiety producing diet pills in anxious individuals may seem counterintuitive, the phenomenon could be explained by a mechanism of action of the drug similar to that of psychostumilants, often used to treat Attention Deficit/Hyperactivity Disorder. These stimulants, such as methylphenidate (Ritalin) augment the release of dopamine, a neurotransmitter, which beyond improving attention and focus, can impact the pleasure system of the brain, providing feelings of enjoyment and reinforcement (Meyer \& Quenzer, 2005) — thus potentially leading to further diet pill use. 
Our fourth hypothesis stated that diet pill use would be associated positively with Axis I disorders, in particular major depression, anxiety disorders, substance use disorders. Our results support this hypothesis in part, indicating that diet pill use is positively associated with anxiety disorders and substance use disorders. Lack of a positive association between diet pill use and depression may be due to the idea that depressed individuals may be more sedentary and less likely to engage in the behaviors that make diet pills available (e.g., going out to the store and purchasing diet pills). Alternately, of the 916 individuals in the sample with major depressive disorder, $22 \%$ had a RAN diagnosis, $16 \%$ had a PAN diagnosis, $9 \%$ had a BAN diagnosis, $19 \%$ had a PBN diagnosis, $1 \%$ had a NPBN diagnosis, $29 \%$ had an ANBN diagnosis, and $4 \%$ had an ED-NOS diagnosis. Given that the two highest frequencies of depressed individuals are members of the RAN and ANBN subgroups, a common characteristic of individuals in these groups may explain the lack of a positive association between diet pill use and depression. Tozzi et al. (2005) found that individuals with a lifetime ANBN diagnosis can be differentiated by diagnostic crossover---whether their $\mathrm{AN}$ preceded the $\mathrm{BN}$ or visa versa, and reported that low levels of novelty seeking were associated with crossover form BN to AN. Given that this study found novelty seeking to be positively associated with diet pill use, and that individuals with restricting-type AN are less likely to use diet pills than other subtypes, it is possible that a lack of association between diet pill use and depression is due to the frequency of depressed individuals in the RAN subgroup, combined with BN to AN crossovers in the ANBN subgroup---all characterized by low novelty seeking behavior. However, this theory is challenged by other studies which suggest that current or lifetime comorbidity of depressive disorders does not differ across AN subtypes (Godart et al., 2006; Wagner et al., 2006). 
In terms of Axis II disorders, we hypothesized that diet pill use would be associated positively with cluster B disorders. Again, our data partially supported this hypothesis, showing a positive association between diet pill use and BPD. Somewhat surprisingly, our data indicated a negative association between diet pill use and NPD.

In terms of anxiety disorders, the association with diet pills use might be explained by the idea that the usage of these drugs may function to imitate and reinforce anxious states, as previously supported by data from animal studies (Vautrin et al., 2005). Thusly, limiting use of these drugs may be particularly relevant in the treatment of individuals predisposed to elevated anxiety.

In terms of the association between diet pill use and substance use disorders, characteristics which make other drug use favorable may also lead to diet pill use. An association between substance use disorders and bulimia nervosa has been widely reported (Cassin \& von Ranson, 2005), and the additional use of diet pills by these individuals further supports the hypothesis that these disorders may share underlying risk factors, such as impulsivity or shared neural reward pathways (Bulik, 1992; Conason, Brunstein Klomek, \& Sher, 2006; Gold, Frost-Pineda, \& Jacobs, 2003).

Regarding the association between diet pill use and BPD, the impulsive/risky behaviors often displayed by individuals with this disorder may make diet pill use more likely. This relationship may function similarly to that found between BPD and laxative abuse, suggesting that specific features of BPD, including suicidality and self-harm, feelings of emptiness, and anger, may also motivate diet pill use (Tozzi et al., 2006).

Narcissistic personality disorder was negatively associated with diet pill use. Of the 21 individuals in the sample with narcissistic personality disorder, $14 \%$ had a RAN diagnosis, $10 \%$ 
had a PAN diagnosis, $14 \%$ had a BAN diagnosis, $14 \%$ had a PBN diagnosis, $38 \%$ had an ANBN diagnosis, and 10\% had an ED-NOS diagnosis. Given our small sample size of individuals with NPD, theorizing further about the association between NPD, diet pill use and ED subtype would be imprudent. However, in general, given the relative absence of self-destructive and impulsive characteristics associated with NPD as compared to other cluster B personality disorders (APA, 1994), this trait may lead individuals with NPD to avoid diet pills, given the potential risks associated with using these uncontrolled substances. Alternately, with NPD characterized by grandiosity and inflated self-worth, individuals with NPD and comorbid ED may tend to use weight loss methods which are more pro-active and self-directed---such as restricting, or excessive exercise. Such self-governing behaviors may potentially yield an increased sense of accomplishment and self-praise in these individuals, whereas diet pill use would be perceived as passive, simple, or inferior.

\section{Limitations of the Study}

Although this study has several strengths, limitations must be considered. The crosssectional design necessitated retrospective reports which are susceptible to recall bias. Moreover, it is possible that our assessment of diet pill use may underestimate frequency of use. Self-report assessment has been shown to underestimate laxative use as compared to urine screening in individuals with AN (Turner, Batik, Palmer, Forbes, \& McDermott, 2000). Finally, in this study, diet pill use was assessed by interview and it is unknown whether structured interview reports are superior to self-report of diet pill use.

In addition to interpreting this study's results from the perspective of statistical significance-whether the results of a statistical analyses meet a defined criterion level, it is also important to consider the magnitude of clinical significance. Clinical significance has been defined by 
Kendall \& Grove (1988) as the point when a patient group "... after treatment, [is] not distinguishable from a meaningful and representative non-disturbed reference group." Though it is useful to adopt the widespread statistical practice of reporting effect sizes, it is important to understand their limitations---a means to an end in addressing clinical questions. Examining alternate methodological approaches is necessary to analyze data in a manner which is both statistically interpretable and clinically significant. Ultimately, determining a threshold for clinical significance for diet pill use in individual in EDs could provide guidelines for designing future studies, and aid treatment providers in applying research to practice (Kraemer \& Kupfer, 2006).

Though conducting these analyses was beyond the scope of this study, considering the parameters of our reported statistics is relevant for future studies, and clinical application. Albeit not an absolute solution, within-field discussion to facilitate defining a threshold of clinical significance is imperative in establishing guidelines for future related studies, evaluating research, and clinical decision making (Kraemer \& Kupfer, 2006). Adding to the clinical knowledge of diet pill use in individuals with EDs, this study should be built upon with the goal of developing a threshold of clinical significance to be used in future power analyses in the field.

\section{Conclusions.}

From a non-statistical perspective however, our results do show robust differences across ED subtypes in use of these substances. In conclusion, diet pill use in individuals with eating disorders is associated with vomiting and purging behavior, novelty seeking, an anxious disposition, and the use of additional weight loss strategies. Given the observed frequency of diet pill use, clinicians should be especially vigilant in individuals who use purgative strategies (vomiting, diuretics, laxatives, emetics), or show signs of comorbid BPD, anxiety or substance 
use disorders, and always ask the screening questions for diet pill use. Similarly, in individuals who exhibit impulsive characteristics or risky behaviors, assessment of diet pill use-including brand, source, and dosage, should be included.

As the potential danger of diet pills has been underplayed given their status as legal substances, screening for diet pill use has been overlooked and minimized clinically. However, given our illustration of the prevalence of diet pill use in individuals with EDs, clear differences in use across ED subtypes, and review of the potential associated health risks in an ED population, assessment of these substances is necessary to provide comprehensive treatment to individuals with EDs. Future studies should include more detailed screening about what types of diet products are used, and how individuals who use these drugs function in terms of ED slips and relapses. Considering the pernicious health risk potential of diet pill use in individuals with eating disorders, the research and clinical objective of reducing this dangerous behavior is imperative. 
Table 1. Demographic characteristics by ED subgroup.

\begin{tabular}{|c|c|c|c|c|c|c|c|}
\hline & $\begin{array}{c}\text { RAN } \\
\text { N=319 } \\
\text { M (SD) }\end{array}$ & $\begin{array}{l}\text { PAN } \\
\text { N=199 } \\
\text { M (SD) }\end{array}$ & $\begin{array}{c}\text { BAN } \\
\mathrm{N}=123 \\
\mathrm{M}(\mathrm{SD})\end{array}$ & $\begin{array}{c}\text { PBN } \\
\text { N=256 } \\
\text { M (SD) }\end{array}$ & $\begin{array}{l}\text { NPBN } \\
\text { N=22 } \\
\text { M (SD) }\end{array}$ & $\begin{array}{l}\text { ANBN } \\
\text { N=361 } \\
\text { M (SD) }\end{array}$ & $\begin{array}{l}\text { EDNOS } \\
\text { N=65 } \\
\text { M (SD) }\end{array}$ \\
\hline Age* & $\begin{array}{r}24.97 \\
(7.83)\end{array}$ & $\begin{array}{r}26.47 \\
(7.76)\end{array}$ & $\begin{array}{r}27.93 \\
(8.57)\end{array}$ & $\begin{array}{l}27.55 \\
(8.69)\end{array}$ & $\begin{array}{r}28.64 \\
(10.71)\end{array}$ & $\begin{array}{r}28.96 \\
(8.70)\end{array}$ & $\begin{array}{r}27.09 \\
(8.80)\end{array}$ \\
\hline $\begin{array}{l}\text { Age of } \\
\text { Onset }\end{array}$ & $\begin{array}{l}16.28 \\
(3.43)\end{array}$ & $\begin{array}{l}16.25 \\
(2.84)\end{array}$ & $\begin{array}{r}16.64 \\
(3.19)\end{array}$ & $\begin{array}{l}17.59 \\
(3.57)\end{array}$ & $\begin{array}{l}19.55 \\
(5.65)\end{array}$ & $\begin{array}{l}17.08 \\
(3.78)\end{array}$ & $\begin{array}{l}17.29 \\
(3.36)\end{array}$ \\
\hline $\begin{array}{l}\text { Lowest } \\
\text { BMI }\end{array}$ & $\begin{array}{l}13.79 \\
(1.90)\end{array}$ & $\begin{array}{l}14.15 \\
(1.96)\end{array}$ & $\begin{array}{l}13.72 \\
(2.00)\end{array}$ & $\begin{array}{l}19.35 \\
(1.70)\end{array}$ & $\begin{array}{l}19.25 \\
(1.99)\end{array}$ & $\begin{array}{r}15.06 \\
(1.89)\end{array}$ & $\begin{array}{r}19.01 \\
(1.49)\end{array}$ \\
\hline $\begin{array}{l}\text { Current } \\
\text { BMI* }\end{array}$ & $\begin{array}{l}17.99 \\
(2.84)\end{array}$ & $\begin{array}{r}18.34 \\
(2.55)\end{array}$ & $\begin{array}{r}18.30 \\
(2.63)\end{array}$ & $\begin{array}{l}22.76 \\
(2.97)\end{array}$ & $\begin{array}{l}22.09 \\
(2.95)\end{array}$ & $\begin{array}{r}19.90 \\
(2.67)\end{array}$ & $\begin{array}{l}21.94 \\
(2.63)\end{array}$ \\
\hline $\begin{array}{l}\text { Highest } \\
\text { BMI }\end{array}$ & $\begin{array}{l}21.05 \\
(2.51)\end{array}$ & $\begin{array}{r}21.43 \\
(2.39)\end{array}$ & $\begin{array}{l}21.17 \\
(2.19)\end{array}$ & $\begin{array}{r}25.52 \\
(3.20)\end{array}$ & $\begin{array}{r}25.97 \\
(3.42)\end{array}$ & $\begin{array}{l}23.14 \\
(2.74)\end{array}$ & $\begin{array}{l}24.18 \\
(3.17)\end{array}$ \\
\hline $\begin{array}{l}\text { Duration } \\
\text { of Illness }\end{array}$ & $\begin{array}{r}7.33 \\
(6.64)\end{array}$ & $\begin{array}{r}9.29 \\
(7.29)\end{array}$ & $\begin{array}{r}9.76 \\
(7.90)\end{array}$ & $\begin{array}{r}8.27 \\
(7.74)\end{array}$ & & $\begin{array}{r}10.49 \\
(7.48)\end{array}$ & \\
\hline
\end{tabular}

Note. RAN = Restricting type, Anorexia Nervosa; BAN = Binging type, Anorexia Nervosa $\mathrm{PBN}=$ Purging type, Anorexia Nervosa; NPBN = Non-purging type, Bulimia Nervosa; ANBN = Anorexia Nervosa, Bulimia Nervosa; NOS1, NOS 2, NOS3 = Eating Disorder Not-OtherwiseSpecified: Types 1,2 , and 3 $*=$ at time of interview; $=$ missing data 
Table 2. Frequency of diet pill use across ED subgroups.

\begin{tabular}{|l|r|}
\hline \multicolumn{1}{|c|}{ ED Diagnosis } & Diet Pill Use (n) \\
\hline RAN & $7.9 \%(25)$ \\
\hline PAN & $41 \%(81)$ \\
\hline BAN & $35 \%(43)$ \\
\hline PBN & $44 \%(113)$ \\
\hline NPBN & $23 \%(5)$ \\
\hline ANBN & $42 \%(152)$ \\
\hline NOS1, NOS2, NOS3 & $20 \%(13)$ \\
\hline
\end{tabular}

Note. $\mathrm{RAN}=$ Restricting type, Anorexia Nervosa; BAN = Binging type, Anorexia Nervosa $\mathrm{PBN}=$ Purging type, Anorexia Nervosa; NPBN = Non-purging type, Bulimia Nervosa; ANBN = Anorexia Nervosa, Bulimia Nervosa; NOS1, NOS 2, NOS3 = Eating Disorder Not-OtherwiseSpecified: Types 1, 2, and 3 
Graph 1. Age-adjusted rates of diet pill use across ED subgroups.

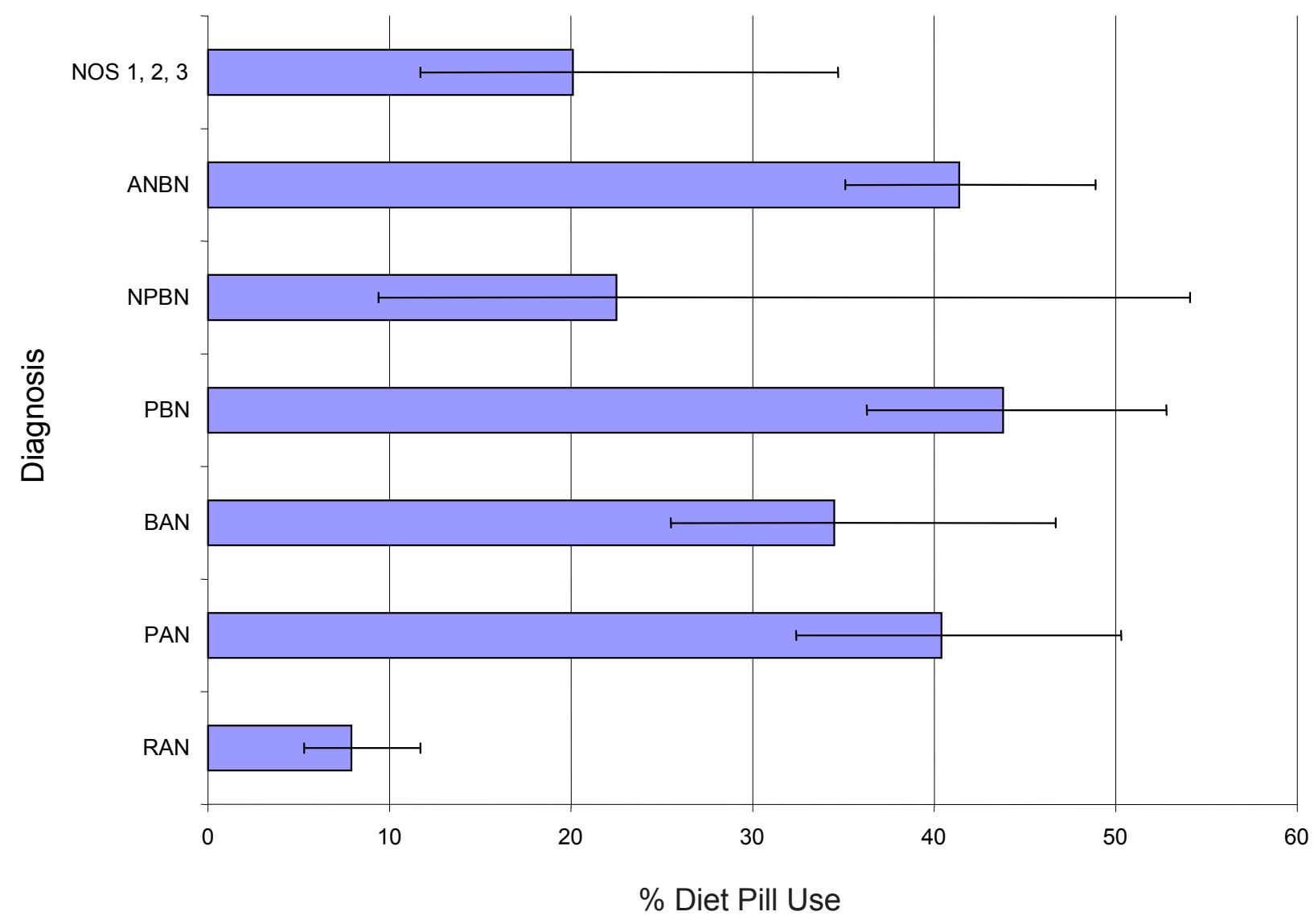

$+-+=95 \%$ confidence intervals 
Table 3. Results from logistic regression analysis (using GEE) predicting odds of diet pill use by vomiting, purging, excessive exercise, tobacco use, caffeine use, and substance use, adjusted for age at interview.

\begin{tabular}{|c|c|c|c|c|}
\hline \multirow[b]{2}{*}{ Variable (n) } & \multicolumn{2}{|c|}{ Diet Pill Users } & \multirow[b]{2}{*}{ Chi-Square (p) } & \multirow[b]{2}{*}{ OR $(95 \%$ CI $)$} \\
\hline & $\begin{array}{c}\text { Behavior } \\
\text { Absent }\end{array}$ & $\begin{array}{c}\text { Behavior } \\
\text { Present }\end{array}$ & & \\
\hline Vomiting (848) & $42.8 \%$ & $14.3 \%$ & $40.99(<0.0001)$ & $2.89(2.09-4.00)$ \\
\hline Purging (630) & $49.7 \%$ & $17.0 \%$ & $47.87(<0.0001)$ & $3.03(2.23-4.10)$ \\
\hline $\begin{array}{l}\text { Excessive } \\
\text { Exercise (533) }\end{array}$ & $34.7 \%$ & $30.7 \%$ & $1.33(0.25)$ & $1.17(0.90-1.53)$ \\
\hline $\begin{array}{l}\text { Tobacco Use } \\
\text { (308) }\end{array}$ & $45.1 \%$ & $28.4 \%$ & $1.58(0.21)$ & $1.23(0.90-1.67)$ \\
\hline $\begin{array}{l}\text { Caffeine Use } \\
(967)\end{array}$ & $37.2 \%$ & $19.1 \%$ & $20.80(<0.0001)$ & $2.18(1.55-3.06)$ \\
\hline $\begin{array}{l}\text { Alcohol Abuse } \\
\text { or Dependence } \\
\text { (376) }\end{array}$ & $46.8 \%$ & $26.3 \%$ & $0.33(0.57)$ & $1.10(0.80-1.51)$ \\
\hline $\begin{array}{l}\text { Cannabis Use* } \\
\text { (251) }\end{array}$ & $53.0 \%$ & $27.4 \%$ & $9.86(0.001)$ & $1.82(1.27-2.61)$ \\
\hline $\begin{array}{l}\text { Any Substance } \\
\text { Use }^{* *}(234)\end{array}$ & $62.8 \%$ & $25.7 \%$ & $22.26(<0.0001)$ & $2.53(1.75-3.63)$ \\
\hline
\end{tabular}

*Frequency $=10$ times or more; **Other than alcohol or cannabis; adjusted for drug use 
Table 4. Results from logistic regression analyses (using GEE) predicting odds of diet pill use by trait anxiety scores and novelty seeking scores, adjusted for ED subtype and age at interview.

\begin{tabular}{|c|c|c|}
\hline Variable (n) & Chi-Square (p) & OR $(95 \%$ CI) \\
\hline $\begin{array}{l}\text { State-Trait } \\
\text { Anxiety } \\
\text { Inventory: } \\
\text { Trait Anxiety } \\
\text { (1300) }\end{array}$ & $11.67(0.0007)$ & $1.02(1.01-1.03)$ \\
\hline $\begin{array}{l}\text { Temperament } \\
\text { and Character } \\
\text { Index: } \\
\text { Novelty Seeking } \\
\text { (1310) }\end{array}$ & $6.43(0.01)$ & $1.02(1.01-1.02)$ \\
\hline
\end{tabular}


Table 5. Results from logistic regression analyses (using GEE) predicting odds of diet pill use by Axis I and Axis II disorders, adjusted for ED subtype and age at interview

\begin{tabular}{|c|c|c|c|c|}
\hline & \multicolumn{2}{|c|}{ \% Diet Pill Use } & \multirow[b]{2}{*}{ Chi-Square (p) } & \multirow[b]{2}{*}{ OR (CI) } \\
\hline Variable (n) & $\begin{array}{l}\text { Disorder } \\
\text { Present }\end{array}$ & $\begin{array}{l}\text { Disorder } \\
\text { Absent }\end{array}$ & & \\
\hline Depression & $21.5 \%$ & $30.8 \%$ & $2.77(0.10)$ & $1.34(0.94-1.92)$ \\
\hline $\begin{array}{l}\text { Any Anxiety } \\
\text { Disorder (844) }\end{array}$ & $36.6 \%$ & $24.7 \%$ & $4.57(0.03)$ & $1.37(1.03-1.83)$ \\
\hline Bipolar I (18) & $50 \%$ & $31.9 \%$ & $0.03(0.87)$ & $1.09(0.39-3.09)$ \\
\hline Bipolar II (22) & $54.5 \%$ & $31.7 \%$ & $0.65(0.42)$ & $1.55(0.54-4.42)$ \\
\hline $\begin{array}{l}\text { Alcohol Abuse or } \\
\text { Dependence (376) }\end{array}$ & $46.8 \%$ & $26.3 \%$ & $1.06(0.30)$ & $1.19(0.86-1.64)$ \\
\hline Cannabis Use* (251) & $53 \%$ & $27.4 \%$ & $3.57(0.06)$ & $1.43(1.0-2.05)$ \\
\hline $\begin{array}{l}\text { Any substance use* } \\
\text { (234) }\end{array}$ & $62.8 \%$ & $25.7 \%$ & $21.90(<0.0001)$ & $2.47(1.73-3.52)$ \\
\hline $\begin{array}{l}\text { Antisocial } \\
\text { Personality Disorders } \\
\text { (PD) (10) }\end{array}$ & $70 \%$ & $32.2 \%$ & $0.26(0.61)$ & $1.47(0.31-7.03)$ \\
\hline Borderline PD (136) & $56.6 \%$ & $29.7 \%$ & $7.26(0.006)$ & $1.90(1.21-2.99)$ \\
\hline Histrionic PD (13) & $69.2 \%$ & $32.2 \%$ & $2.44(0.12)$ & $3.08(0.87-10.94)$ \\
\hline Narcissistic PD (21) & $19 \%$ & $32.8 \%$ & $5.78(0.03)$ & $0.25(0.07-0.86)$ \\
\hline
\end{tabular}

$*$ Frequency $=10$ times or more; $* *$ Other than alcohol or cannabis 


\section{REFERENCES}

Abrams, B., \& Laros, R. (1986). Prepregnancy weight, weight gain, and birth weight. American Journal of Obstetrics and Gynecology, 154, 503-509.

American Psychiatric Association. (1994). Diagnostic and Statistical Manual of Mental Disorders. Fourth Edition. Washington, D.C.: American Psychiatric Association Press.

Andersen, T. (2003). Are newer drugs better drugs? Obesity Reviews, 4(2), 75.

Bergen, A. W., van den Bree, M. B., Yeager, M., Welch, R., Ganjei, J. K., Haque, K., et al. (2003). Candidate genes for anorexia nervosa in the 1p33-36 linkage region: serotonin $1 \mathrm{D}$ and delta opioid receptor loci exhibit significant association to anorexia nervosa. Molecular Psychiatry, 8(4), 397-406.

Berkson, J. (1946). Limitations of the application of fourfold table analysis to hospital data. Biometrics, 2, 47-53.

Birmingham, C. L., Su, J., Hlynsky, J. A., Goldner, E. M., \& Gao, M. (2005). The mortality rate from anorexia nervosa. International Journal of Eating Disorders, 38(2), 143-146.

Blanck, H., Khan, L. K., \& Serdula, M. (2005). Use of Nonprescription Weight Loss Products: Results from a Multistate Survey. JAMA, 286(8), 930-935.

Braun, D. L., Sunday, S. R., \& Halmi, K. A. (1994). Psychiatric comorbidity in patients with eating disorders. Psychological Medicine, 24, 859-867.

Brewerton, T., Lydiard, R., Herzog, D. B., Brotman, A., O'Neil, P., \& Ballenger, J. (1995). Comorbidity of Axis I psychiatric disorders in bulimia nervosa. Journal of Clinical Psychiatry, 56, 77-80.

Bulik, C. M. (1987a). Alcohol use and depression in women with bulimia. American Journal of Drug and Alcohol Abuse, 13, 343-355.

Bulik, C. M. (1987b). Drug and alcohol abuse by bulimic women and their families. American Journal of Psychiatry, 144, 1604-1606.

Bulik, C. M. (1992). Abuse of drugs associated with eating disorders. Journal of Substance Abuse, 4, 69-90.

Bulik, C. M., Bacanu, S. A., Klump, K. L., Fichter, M. M., Halmi, K. A., Keel, P., et al. (2005). Selection of eating-disorder phenotypes for linkage analysis. American Journal of Medical Genetics, 139(1), 81-87.

Bulik, C. M., Sullivan, P. F., Epstein, L. H., McKee, M., Kaye, W. H., Dahl, R. E., et al. (1992). Drug use in women with anorexia and bulimia nervosa. International Journal of Eating Disorders, 11, 213-225. 
Bulik, C. M., Sullivan, P. F., Fear, J., \& Pickering, A. (1997). Predictors of the development of bulimia nervosa in women with anorexia nervosa. Journal of Nervous and Mental Disease, 185, 704-707.

Carek, P., \& Dickerson, L. (1999). Current Concepts in the Pharmacological Management of Obesity. Drugs, 57(6), 883-904.

Casper, R., Hedeker, D., \& McClough, J. (1992). Personality dimensions in eating disorders and their relevance for subtyping. Journal of the American Academy of Child and Adolescent Psychiatry, 31(5), 830-840.

Cassin, S. E., \& von Ranson, K. M. (2005). Personality and eating disorders: a decade in review. Clinical Psychology Review, 25(7), 895-916.

Charney, D. S., Woods, S. W., Goodman, W. K., \& Heninger, G. R. (1987). Serotonin function in anxiety. II. Effects of the serotonin agonist MCPP in panic disorder patients and healthy subjects. Psychopharmacology, 92(1), 14-24.

Chial, H. J., McAlpine, D. E., \& Camilleri, M. (2002). Anorexia nervosa: manifestations and management for the gastroenterologist. American Journal of Gastroenterology, 97(2), 255-269.

Cloninger, C. R., Przybeck, T. R., Svrakic, D. M., \& Wetzel, R. D. (1994). The Temperament and Character Inventory (TCI): A Guide to its Development and Use. St. Louis, MO: Center for Psychobiology of Personality. Washington University.

Cohen, J. (1988). Statistical Power Analysis for the Behavioral Sciences (2nd ed.). Hillsdale, NJ: Lawrence Erlbaum Associates.

Conason, A. H., Brunstein Klomek, A., \& Sher, L. (2006). Recognizing alcohol and drug abuse in patients with eating disorders. Quarterly Journal of Medicine, 99(5), 335-339.

Cuthbert, M. F. (1980). Anorectic and decongestant preparations containing phenylpropanolamine. Lancet, 1(8164), 367.

Davis, C., \& Kaptein, S. (2006). Anorexia nervosa with excessive exercise: a phenotype with close links to obsessive-compulsive disorder. Psychiatry Research, 142(2-3), 209-217.

Diaz-Marsa, M., Carrasco, J. L., \& Saiz, J. (2000). A study of temperament and personality in anorexia and bulimia nervosa. Journal of Personality Disorders, 14(4), 352-359.

Dietz, A. J., Jr. (1981). Amphetamine-like reactions to phenylpropanolamine. Journal of the American Medical Association, 245(6), 601-602.

Diggle, P., Liang, K., \& Zeger, S. (1994). Analysis of Longitudinal Data. Oxford: Oxford Science. 
Dwyer, J. T., Allison, D. B., \& Coates, P. M. (2005). Dietary supplements in weight reduction. Journal of the American Dietetic Association, 105(5 Suppl 1), S80-86.

Eckert, E. D., Halmi, K. A., Marchi, P., Grove, W., \& Crosby, R. (1995). Ten-year follow-up of anorexia nervosa: clinical course and outcome. Psychological Medicine, 25, 143-156.

Eddy, K., Keel, P., Dorer, D., Delinsky, S., Franko, D., \& Herzog, D. (2002). Longitudinal comparison of anorexia nervosa subtypes. International Journal of Eating Disorders, 31, 191-201.

Edwards, A. L. (1957). Social desirability and probability of endorsement of items in the interpersonal check list. Journal of Abnormal Psychology, 55(3), 394-396.

Eisenberg, D. M., Davis, R. B., Ettner, S. L., Appel, S., Wilkey, S., Van Rompay, M., et al. (1998). Trends in alternative medicine use in the United States, 1990-1997: results of a follow-up national survey. Journal of the American Medical Association, 280(18), 15691575.

Fagerstrom, K.-O. (1978). Measuring degree of physical dependence to tobacco smoking with reference to individualization of treatment. Addictive Behaviors, 3, 235-241.

Fairburn, C., \& Walsh, B. (2002). Atypical eating disorders (eating disorders not otherwise specified). In Fairburn C \& B. K (Eds.), Eating Disorders and Obesity: A Comprehensive Handbook, 2nd Edition (pp. 171-177.). New York: Guilford Press.

Federal Trade Commission, U. S. (2002). Weight-loss advertising [electronic resource] : an analysis of current trends / [a report of the staff of the Federal Trade Commission; principal authors, Richard L. Cleland ... et al.].

Fichter, M. M., Herpertz, S., Quadflieg, N., \& Herpertz-Dahlmann, B. (1998). Structured interview for anorexic and bulimic disorders for DSM-IV and ICD-10: updated (third) revision. International Journal of Eating Disorders, 24, 227-249.

Fichter, M. M., \& Noegel, R. (1990). Concordance for bulimia nervosa in twins. International Journal of Eating Disorders, 9(3), 255-263.

Fichter, M. M., Quadflieg, N., \& Rief, W. (1994). Course of multi-impulsive bulimia. Psychological Medicine, 24(3), 591-604.

First, M. B., Gibbon, M., Spitzer, R. L., Williams, J. B. M., \& Benjamin, L. S. (1997). Structured Clinical Interview for DSM-IV Axis-II Personality Disorders (SCID-II).

First, M. B., Spitzer, R. L., Gibbon, M., \& Williams, J. B. W. (1997). Structured Clinical Interview for DSM-IV Axis I Disorders, Research Version, Patient Edition. New York: Biometrics Research, New York State Psychiatric Institute. 
Gendall, K. A., Joyce, P. R., Carter, F. A., McIntosh, V. V., \& Bulik, C. M. (2005). Childhood gastrointestinal complaints in women with bulimia nervosa. International Journal of Eating Disorders, 37(3), 256-260.

Godart, N. T., Berthoz, S., Rein, Z., Perdereau, F., Lang, F., Venisse, J. L., et al. (2006). Does the frequency of anxiety and depressive disorders differ between diagnostic subtypes of anorexia nervosa and bulimia? International Journal of Eating Disorders.

Godart, N. T., Flament, M. F., Lecrubier, Y., \& Jeammet, P. (2000). Anxiety disorders in anorexia nervosa and bulimia nervosa: co-morbidity and chronology of appearance. European Psychiatry, 15(1), 38-45.

Gold, M. S., Frost-Pineda, K., \& Jacobs, W. S. (2003). Overeating, binge eating, and eating disorders as addictions. Psychiatric Annals, 33, 117-122.

Halmi, K. A., Sunday, S. R., Strober, M., Kaplan, A., Woodside, D. B., Fichter, M. M., et al. (2000). Perfectionism in anorexia nervosa: variation by clinical subtype, obsessionality, and pathological eating behavior. American Journal of Psychiatry, 157(11), 1799-1805.

Hebebrand, J., Himmelmann, G. W., Heseker, H., Schafer, H., \& Remschmidt, H. (1996). Use of percentiles for the body mass index in anorexia nervosa: diagnostic, epidemiological, and therapeutic considerations. International Journal of Eating Disorders, 19, 359-369.

Herzog, D. B., Keller, M. B., Sacks, N. R., Yeh, C. J., \& Lavori, P. W. (1992). Psychiatric comorbidity in treatment-seeking anorexics and bulimics. Journal of the American Academy of Child and Adolescent Psychiatry, 31(5), 810-818.

Herzog, D. B., Sacks, N. R., Keller, M. B., Lavori, P. W., von Ranson, K. B., \& Gray, H. M. (1992). Patterns and predictors of recovery in anorexia nervosa and bulimia nervosa. Journal of the American Academy of Child and Adolescent Psychiatry, 32(4), 835-842.

Hoek, H. W. (2006). Incidence, prevalence and mortality of anorexia nervosa and other eating disorders. Current Opinions in Psychiatry, 19(389-394).

Howrie, D. L., \& Wolfson, J. H. (1983). Phenylpropanolamine-induced hypertensive seizures. Journal of Pediatrics, 102(1), 143-145.

Johnson, D. A., Etter, H. S., \& Reeves, D. M. (1983). Stroke and phenylpropanolamine use. Lancet, 2(8356), 970.

Jones, J. M., Bennett, S., Olmsted, M. P., Lawson, M. L., \& Rodin, G. (2001). Disordered eating attitudes and behaviours in teenaged girls: a school-based study. Clinical Journal of American Medicine, 165(5), 547-552. 
Kann, L., Kinchen, S. A., Williams, B. I., Ross, J. G., Lowry, R., Grunbaum, J. A., et al. (2000). Youth risk behavior surveillance--United States, 1999. MMWR Centers of Disease Control Surveillance Summaries, 49(5), 1-32.

Kaye, W. H., Bailer, U. F., Frank, G. K., Wagner, A., \& Henry, S. E. (2005). Brain imaging of serotonin after recovery from anorexia and bulimia nervosa. Physiological Behavior, 86(1-2), 15-17.

Kaye, W. H., Bertram, K., Bulik, C. M., Devlin, B., Bacanu, S., Thornton, L., et al. (2005). Anxiety disorders in bulimia and anorexia nervosa. American Journal of Psychiatry.

Kaye, W. H., Devlin, B., Barbarich, N., Bulik, C. M., Thornton, L., Bacanu, S. A., et al. (2004). Genetic analysis of bulimia nervosa: methods and sample description. Int J Eat Disord, 35(4), 556-570.

Kaye, W. H., Frank, G. K., Bailer, U. F., Henry, S. E., Meltzer, C. C., Price, J. C., et al. (2005). Serotonin alterations in anorexia and bulimia nervosa: new insights from imaging studies. Physiol Behav., 85(1), 73-81.

Keel, P. K., Klump, K. L., Miller, K. B., McGue, M., \& Iacono, W. G. (2005). Shared transmission of eating disorders and anxiety disorders. International Journal of Eating Disorders, 38(2), 99-105.

Kendall, P. C., \& Grove, W. M. (1988). Normative comparisons in therapy outcome. Behavioral Assessment, 10, 147-158.

Khan, L. K., Serdula, M. K., Bowman, B. A., \& Williamson, D. F. (2001). Use of prescription weight loss pills among U.S. adults in 1996-1998. Annals of International Medicine, 134(4), 282-286.

Klump, K. L., Bulik, C. M., Pollice, C., Halmi, K. A., Fichter, M. M., Berrettini, W. H., et al. (2000). Temperament and character in women with anorexia nervosa. Journal of Nervous Mental Disorders, 188(9), 559-567.

Klump, K. L., Wonderlich, S., Lehoux, P., Lilenfeld, L. R., \& Bulik, C. M. (2002). Does environment matter? A review of nonshared environment and eating disorders. International Journal of Eating Disorders, 31(2), 118-135.

Kraemer, H. C., \& Kupfer, D. J. (2006). Size of treatment effects and their importance to clinical research and practice. Biological Psychiatry, 59(11), 990-996.

Laessle, R., Wittchen, H., Fichter, M. M., \& Pirke, K. (1989). The significance of subgroups of bulimia and anorexia nervosa: lifetime prevalence of psychiatric disorders. International Journal of Eating Disorders, 8, 569-574. 
le Grange, D., Binford, R. B., Peterson, C. B., Crow, S. J., Crosby, R. D., Klein, M. H., et al. (2006). DSM-IV threshold versus subthreshold bulimia nervosa. International Journal of Eating Disorders.

le Grange, D., Loeb, K. L., Van Orman, S., \& Jellar, C. C. (2004). Bulimia nervosa in adolescents: a disorder in evolution? Archives of Pediatric Adolescent Medicine, 158(5), 478-482.

Leibowitz, S. F., \& Shor-Posner, G. (1986). Brain serotonin and eating behavior. Appetite, 7 Supplement, 1-14.

Lewis, J. D., \& Strom, B. L. (2002). Balancing safety of dietary supplements with the free market. Annals of International Medicine, 136(8), 616-618.

Liang, K. Y., \& Zeger, S. L. (1986). Longitudinal data analysis using generalized linear models. Biometrika, 73, 13-22.

Lilenfeld, L. R., Kaye, W. H., Greeno, C. G., Merikangas, K. R., Plotnikov, K., Pollice, C., et al. (1998). A controlled family study of restricting anorexia and bulimia nervosa: comorbidity in probands and disorders in first-degree relatives. Archives of General Psychiatry, 55, 603-610.

Magkos, F., \& Kavouras, S. A. (2004). Caffeine and ephedrine: physiological, metabolic and performance-enhancing effects. Sports Medicine, 34(13), 871-889.

Meyer, J. S., \& Quenzer, L. F. (2005). Psychopharmacology: Drugs, the Brain, and Behavior. Sunderland, MA: Sinauer Associates, Inc.

Mitchell, J. E., \& Crow, S. (2006). Medical complications of anorexia nervosa and bulimia nervosa. Current Opinions in Psychiatry, 19(4), 438-443.

Mitchell, J. E., Pomeroy, C., \& Huber, M. (1988). A clinician's guide to the eating disorders medicine cabinet. International Journal of Eating Disorders, 7, 211-223.

Nakamura, K., Hoshino, Y., Watanabe, A., Honda, K., Niwa, S., \& Yamamoto, M. (1999). Eating problems and related weight control behaviour in adult Japanese women. Psychotherapy and Psychosomatics, 68(1), 51-55.

Neumaerker, K. J. (1997). Mortality and sudden death in anorexia nervosa. International Journal of Eating Disorders, 21, 205-212.

Nunes, M. A., Barros, F. C., Anselmo Olinto, M. T., Camey, S., \& Mari, J. D. (2003). Prevalence of abnormal eating behaviours and inappropriate methods of weight control in young women from Brazil: a population-based study. Eating and Weight Disorders, 8(2), 100106. 
Pilsczek, F. H., Karcic, A. A., \& Freeman, I. (2003). Case report: Dexatrim (Phenylpropanolamine) as a cause of myocardial infarction. Heart and Lung, 32(2), 100104.

Puar, H. S. (1984). Acute memory loss and nominal aphasia caused by phenylpropanolamine. Southern Medical Journal, 77(12), 1604-1605.

Quadflieg, N., \& Fichter, M. M. (2003). The course and outcome of bulimia nervosa. European Child and Adolescent Psychiatry, 12(Supplement 1), I99-I109.

Roerig, J. L., Mitchell, J. E., de Zwaan, M., Wonderlich, S. E., Kamran, S., Engbloom, S., et al. (2003). The Eating Disorders Medicine Cabinet Revisited: A Clinician's Guide to Appetite Suppressants and Diuretics. International Journal of Eating Disorders, 33, 443457.

Rutter, M., Moffitt, T. E., \& Caspi, A. (2006). Gene-environment interplay and psychopathology: multiple varieties but real effects. Journal of Child Psychology and Psychiatry, 47(3-4), 226-261.

SAS Institute, I. (2004). SAS (Version 9.1.3). Cary, NC: SAS Institute Inc.

Schwalberg, M., Barlow, B., Alger, S. A., \& Howard, L. J. (1992). Comparison of bulimics, obese binge eaters, social phobics, and individuals with panic disorder on comorbidity across DSM-III-R anxiety disorders. Journal of Abnormal Psychology, 101(4), 675-681.

Shekelle, P., Hardy, M. L., Morton, S. C., Maglione, M., Mojica, W. A., Suttorp, M. J., et al. (2003). Efficacy and safety of ephedra and ephedrine for weight loss and athletic performance: a meta-analysis. Journal of the American Medical Association, 289(12), $1537-1545$.

Silverstone, T. (1992). Appetite suppressants: A review. Drugs, 43, 820-836.

Spielberger, C., Gorsuch, R., \& Luchene, R. (1970). STAI Manual for the State-Trait Anxiety Inventory. Palo Alto, CA: Consulting Psychologists Press.

Story, M., Hauck, F. R., Broussard, B. A., White, L. L., Resnick, M. D., \& Blum, R. W. (1994). Weight perceptions and weight control practices in American Indian and Alaska Native adolescents. A national survey. Archives of Pediatric Adolescent Medicine, 148(6), 567571.

Strober, M., Freeman, R., Lampert, C., Diamond, J., \& Kaye, W. H. (2000). Controlled family study of anorexia nervosa and bulimia nervosa: evidence of shared liability and transmission of partial syndromes. American Journal of Psychiatry, 157(3), 393-401.

Strober, M., Freeman, R., \& Morrell, W. (1997). The long-term course of severe anorexia nervosa in adolescents: survival analysis of recovery, relapse, and outcome predictors 
over 10- 15 years in a prospective study. International Journal of Eating Disorders, 22(4), 339-360.

Sudakov, S. K., Rusakova, I. V., \& Medvedeva, O. F. (2003). Effect of chronic caffeine consumption on changes in locomotor activity of WAG/G and Fischer-344 rats induced by nicotine, ethanol, and morphine. Bulletin of Experimental Biological Medicine, 136(6), 563-565.

Sullivan, P. F. (1995). Mortality in anorexia nervosa. American Journal of Psychiatry, 152(7), 1073-1074.

Swenson, R. D., Golper, T. A., \& Bennett, W. M. (1982). Acute renal failure and rhabdomyolysis after ingestion of phenylpropanolamine-containing diet pills. Journal of the American Medical Association, 248(10), 1216.

Tauscher, J., Bagby, R. M., Javanmard, M., Christensen, B. K., Kasper, S., \& Kapur, S. (2001). Inverse relationship between serotonin 5-HT(1A) receptor binding and anxiety: a [(11)C]WAY-100635 PET investigation in healthy volunteers. American Journal of Psychiatry, 158(8), 1326-1328.

Tozzi, F., Thornton, L. M., Klump, K. L., Fichter, M. M., Halmi, K. A., Kaplan, A. S., et al. (2005). Symptom fluctuation in eating disorders: correlates of diagnostic crossover. American Journal of Psychiatry, 162(4), 732-740.

Tozzi, F., Thornton, L. M., Mitchell, J. E., Fichter, M. M., Klump, K. L., Lilenfeld, L. R., et al. (2006). Features associated with laxative abuse in individuals with eating disorders. Psychosomatic Medicine, 68(3), 470-477.

Turner, H., \& Bryant-Waugh, R. (2003). Eating disorders not otherwise specified (EDNOS): profiles of clients presenting at a community eating disorders service. European Eating Disorders Review, 12, 18-26.

Turner, J., Batik, M., Palmer, L. J., Forbes, D., \& McDermott, B. M. (2000). Detection and importance of laxative use in adolescents with anorexia nervosa. Journal of the American Academy of Child and Adolescent Psychiatry, 39(3), 378-385.

Valdar, W., Solberg, L. C., Gauguier, D., Cookson, W. O., Rawlins, N. J., Mott, R., et al. (2006). Genetic and environmental effects on complex traits in mice. Genetics.

Vautrin, S., Pelloux, Y., \& Costentin, J. (2005). Preference for caffeine appears earlier in nonanxious than in anxious mice. Neuroscience Letter, 386(2), 94-98.

Wade, T. D., Bulik, C. M., Neale, M., \& Kendler, K. S. (2000). Anorexia nervosa and major depression: Shared genetic and environmental risk factors. American Journal of Psychiatry, 157(3), 469-471. 
Wagner, A., Barbarich-Marsteller, N. C., Frank, G. K., Bailer, U. F., Wonderlich, S. A., Crosby, R. D., et al. (2006). Personality traits after recovery from eating disorders: do subtypes differ? International Journal of Eating Disorders, 39(4), 276-284.

World Health Organization (Ed.). (1992). International Statistical Classification of Diseases and Related Health Problems, tenth revision. Geneva: World Health Organization.

Yates, W. R., Sieleni, B., \& Reich, J. (1989). Comorbidity of bulimia nervosa and personality disorder. Journal of Clinical Psychiatry, 50, 57-59.

Zeger, S. L., Liang, K. Y., \& Albert, P. S. (1988). Models for longitudinal data: a generalized estimating equation approach. Biometrics, 44(4), 1049-1060. 